\title{
Probing supraglacial debris on Mars 1: Sources, thickness, and stratigraphy
}

\author{
David M.H. Baker ${ }^{\mathrm{a}, *}$, Lynn M. Carter ${ }^{\mathrm{b}}$ \\ ${ }^{a}$ NASA Goddard Space Flight Center, Greenbelt, MD 20771, USA \\ ${ }^{\mathrm{b}}$ Lunar and Planetary Laboratory, University of Arizona, Tucson, AZ 85721, USA
}

A R T I C L E I N F O

\section{Keywords:}

Mars

Surface

Geological processes

Ices

Cratering

Radar observations

\begin{abstract}
A B S T R A C T
Geomorphic and geophysical evidence supports a debris-covered glacier origin for a suite of landforms at the mid-latitudes of Mars, including lobate debris aprons (LDA), lineated valley fill (LVF), and concentric crater fill (CCF). These large reservoirs of ice and their near-surface structure provide a rich record for understanding the planet's climate and history of global volatile exchange over the past billion years. LDA, LVF, and CCF are also potential sites for future robotic and human missions but the accessibility of glacial ice for direct sampling and in situ resource utilization depends largely on the geotechnical properties of the surface debris ("supraglacial debris"), including its thickness, grain sizes, and density structure. The physical properties of this supraglacial debris layer have been poorly constrained. We use images of morphology, digital elevation models, thermal inertia data, and radar sounding data to probe the near surface of LDA, LVF, and CCF in Deuteronilus Mensae in order to place constraints on the sources, grain sizes, thickness, and stratigraphy of supraglacial debris. We find evidence for at least a two-layer stratigraphy. Layered mantle consisting of atmospherically emplaced dust and ice superposes boulder-rich sediment sourced by rockfalls glacially transported downslope. High thermal inertia, boulder-rich termini and debris bands reminiscent of medial moraines are found throughout the study region, supporting a rockfall origin for at least a fraction of the debris exposed at the surface. This supraglacial debris layer would have thickened with time from sublimation of glacial ice and liberation of englacial sediment and dust. At present, the entire supraglacial debris package is a minimum of a few meters in thickness and is likely tens of meters in thickness in many locations, possibly thinning regionally at lower latitudes and locally thinning toward the headwalls. The lack of terracing or interior structures in craters formed within LDA, LVF, and CCF and the absence of near-surface reflectors in SHARAD radar data further suggest that no strong contrasts in permittivity or strength occur at the interface of the layers.
\end{abstract}

\section{Introduction}

Current data supports the presence of large-scale glacial landforms within the mid-latitudes of Mars. These features include Lobate Debris Aprons (LDA), Lineated Valley Fill (LVF), and Concentric Crater Fill (CCF) (Sharp, 1973; Squyres, 1978, 1979), which are thought to have formed from thick accumulations of snow and ice during at least the Middle to Late Amazonian Epochs (Head et al., 2010; Lucchitta, 1984). Major geomorphic characteristics support a glacial origin for these features, including integrated flow patterns originating from protected alcoves and extending downslope for tens of kilometers, and convex-up topographic profiles along their centerlines (Lucchitta, 1984; Li et al., 2005; Head et al., 2006a, b, 2010).

More specifically, recent work on the morphology and radar properties of LDA, LVF, and CCF suggest that they are analogous to debriscovered glaciers on Earth (Head et al., 2010), although variations in debris and ice contents are probable (Pierce and Crown, 2003). The hypothesized structure of LDA, LVF, and CCF consist of a surface, or "supraglacial," debris layer that inhibits sublimation of the underlying glacial ice (Fig. 1). Topography data from the Mars Orbiter Laser Altimeter (MOLA) reveal their convex-upward shape (Li et al., 2005) and surface elevation above the surrounding terrains suggestive of viscous flow and average thicknesses of $450 \mathrm{~m}$ (Parsons et al., 2011; Levy et al., 2014). Analyses of Mars Reconnaissance Orbiter (MRO) SHAllow RADar (SHARAD) radar sounding data (Seu et al., 2007) show strong basal reflectors and low loss tangents, interpreted to be consistent with the presence of a nearly pure water ice body hundreds of meters in thickness in contact with underlying bedrock (Holt et al., 2008; Plaut et al., 2009). Recent estimates of the volume of the ice contained in LDA, LVF, and CCF are on the order of $10^{5} \mathrm{~km}^{3}$, or a global equivalent ice layer of 0.9-2.6 m thick (Levy et al., 2014; Karlsson et al., 2015). If the current understanding of their internal structure is correct, LDA,

\footnotetext{
* Corresponding author at: NASA Goddard Space Flight Center, 8800 Greenbelt Rd., Code 698, Greenbelt, MD 20771, USA.

E-mail address: david.m.hollibaughbaker@nasa.gov (D.M.H. Baker).
} 


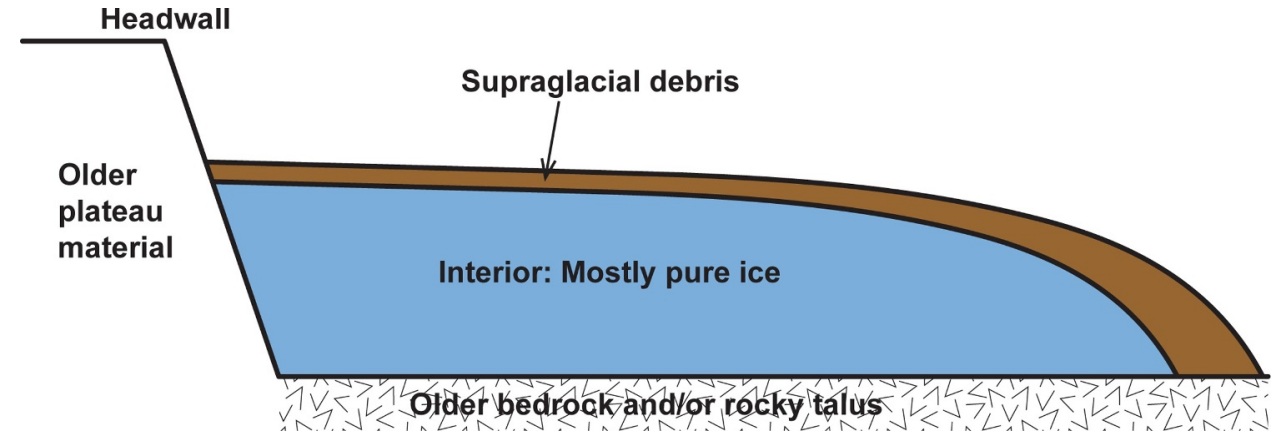

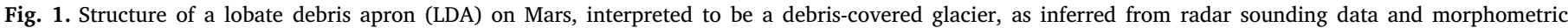
measurements.

LVF, and CCF represent a significant reservoir of non-polar ice that preserves a record of the recent climate on Mars and may be an accessible resource of water for future landed missions to Mars. Human missions to Mars, in particular, require significant non-polar sources of water that would be satisfied by having access to LDA, LVF, and CCF within their scientific exploration zone (Head et al., 2015; Hoffman et al., 2017).

Critical to understanding the accessibility of this ice to future missions are constraints on the physical properties of the supraglacial debris layer, including its thickness, grain size, and stratigraphy (Hoffman et al., 2017). Scientifically, this layer is important for understanding how such massive glacial ice can be preserved for hundreds of millions of years when ice is currently unstable on the surface of the mid-latitudes of Mars (Mellon and Jakosky, 1993). Also, an understanding of the origin and source materials of the debris layers is important for constraining recent episodes of resurfacing and erosion at the mid-latitudes, which are thought to be tied to recent climate changes (Head et al., 2003) and have important implications for interpreting the cratering record and derived model ages of LDA, LVF, and CCF.

For debris-covered glaciers on Earth, supraglacial debris is generally $<2 \mathrm{~m}$ in thickness, collectively consisting of a range of clast sizes from sand to boulders mainly sourced from rockfall and avalanching of rock or rock/ice mixtures at the glacier headwall regions (Mackay et al., 2014; Koutnik et al., 2016). Volcanic ash can also contribute to the debris cover where glaciers are in close proximity to volcanic centers, as occurs in Iceland (e.g., Nield et al., 2013). The supraglacial sediment is typically well-sorted, with fines at the bottom near the ice surface and larger clasts and boulders on top (Mackay et al., 2014; Koutnik et al., 2016). For example, the surfaces of debris-covered glaciers in the Unita Mountains, Utah are found to have fairly uniform clasts sizes with longaxis mean values of generally $>25 \mathrm{~cm}$, or boulder in size (Wentworth grain size classification) (Cardenas et al., 2014). Debris thicknesses also generally thicken toward the termini of the glaciers, as debris is transported downslope away from the headwalls. Ablation and downwasting of glacial ice also leads to thickening of the supraglacial debris layer though liberation of englacial debris and development of a lag deposit. For example, the analog Mullins Valley debris-covered glacier in the Antarctic Dry Valleys (Marchant et al., 2002; Marchant and Head, 2007; Mackay et al., 2014), has a $<1 \mathrm{~m}$ thick surface till layer consisting of poorly consolidated sand- to boulder-sized sediment that is $30 \%$ supra-glacially transported rockfall and $70 \%$ englacially transported rockfall that is liberated through sublimation of the glacial ice. Further, windblown sand can fill thermal contraction cracks, forming sand wedges and contributing to net aggradation or inflation of the surface, as occurs in the Antarctic Dry Valleys (Sletten et al., 2003).

Although supraglacial debris on LDA, LVF, and CCF likely shares similarities with debris-covered glaciers on Earth, differences in feature age, headwall lithologies, past and present climate, and patterns of accumulation and ablation likely have resulted in a much different near-surface structure for glacial features on Mars. Despite recent work attempting to understand the near-surface structure of LDA, LVF, and CCF, many uncertainties remain. The provenance of the supraglacial debris and relative proportions of rockfall material and atmospherically-derived dust and ice are unclear despite much work examining the detailed textures (Mangold, 2003; Pierce and Crown, 2003; Chuang and Crown, 2005; Levy et al., 2009b; Berman et al., 2015). Previous studies also lacked the image resolution to investigate the possible presence of large boulders (down to $\sim 1 \mathrm{~m}$ in size) and finescale layering exposed at the surface. The thickness of the supraglacial debris layer is also poorly constrained. Impact crater morphology (Kress and Head, 2008) has been used to suggest an average thickness of $<15 \mathrm{~m}$ for the supraglacial debris. However, this work was based on a limited area and alternative interpretations of the impact morphology call into question the utility of using crater size-morphology trends for estimating debris layer thickness (Baker and Carter, 2019). Holt et al. (2008) and Plaut et al. (2009) did not observe near-surface reflectors in SHARAD radar data that may represent the contact between supraglacial debris and the underlying glacial ice. Based on this absence, they concluded that the thickness of supraglacial debris must be less than the vertical resolution of SHARAD $(\sim 15 \mathrm{~m}$ in free-space, or $\sim 10 \mathrm{~m}$ in ice). However, a systematic survey of possible near-surface reflections representing the surface debris-ice contact in SHARAD data over LDA, LVF, and CCF has not been conducted. Further, it is possible that the contact between debris and ice lacks a strong dielectric contrast or is more gradational than assumed, resulting in an absence of radar reflections.

In order to provide an improved understanding of the sources, thickness and stratigraphy of supraglacial debris on Mars, we conducted a detailed investigation of the near-surface properties of LDA, LVF, and CCF within Deuteronilus Mensae. This region is host to the greatest areal density of LDA, LVF, and CCF (Squyres, 1979; Levy et al., 2014) and is covered extensively by both SHARAD radar observations and high-resolution images from the MRO Context (CTX) and High Resolution Imaging Science Experiment (HiRISE) cameras (Malin et al., 2007; McEwen et al., 2007). Complete coverage of the region with CTX images at $6 \mathrm{~m} /$ pixel now allow for comprehensive investigation of the morphology of LDA, LVF, and CCF. We first mapped the extent of LDA, $\mathrm{LVF}$, and CCF and assessed the texture and thermophysical properties of the surface, including boulder abundance, to interpret debris sources. We then used well-preserved impact craters $\geq 75 \mathrm{~m}$ in diameter to probe the near-surface layers and to make inferences on grain size, layering, and thickness of the debris. Finally, we conducted a systemic survey of SHARAD radargrams and used simple radar transmission models to evaluate the ability of SHARAD to detect possible contacts between supraglacial debris and glacial ice and to constrain the thickness and dielectric properties of the debris layer. Together, this work provides the first integrated view of the near-surface properties of glacial landforms on Mars. Results will help in the planning of future missions and future detailed investigations of the mid-latitude regions 


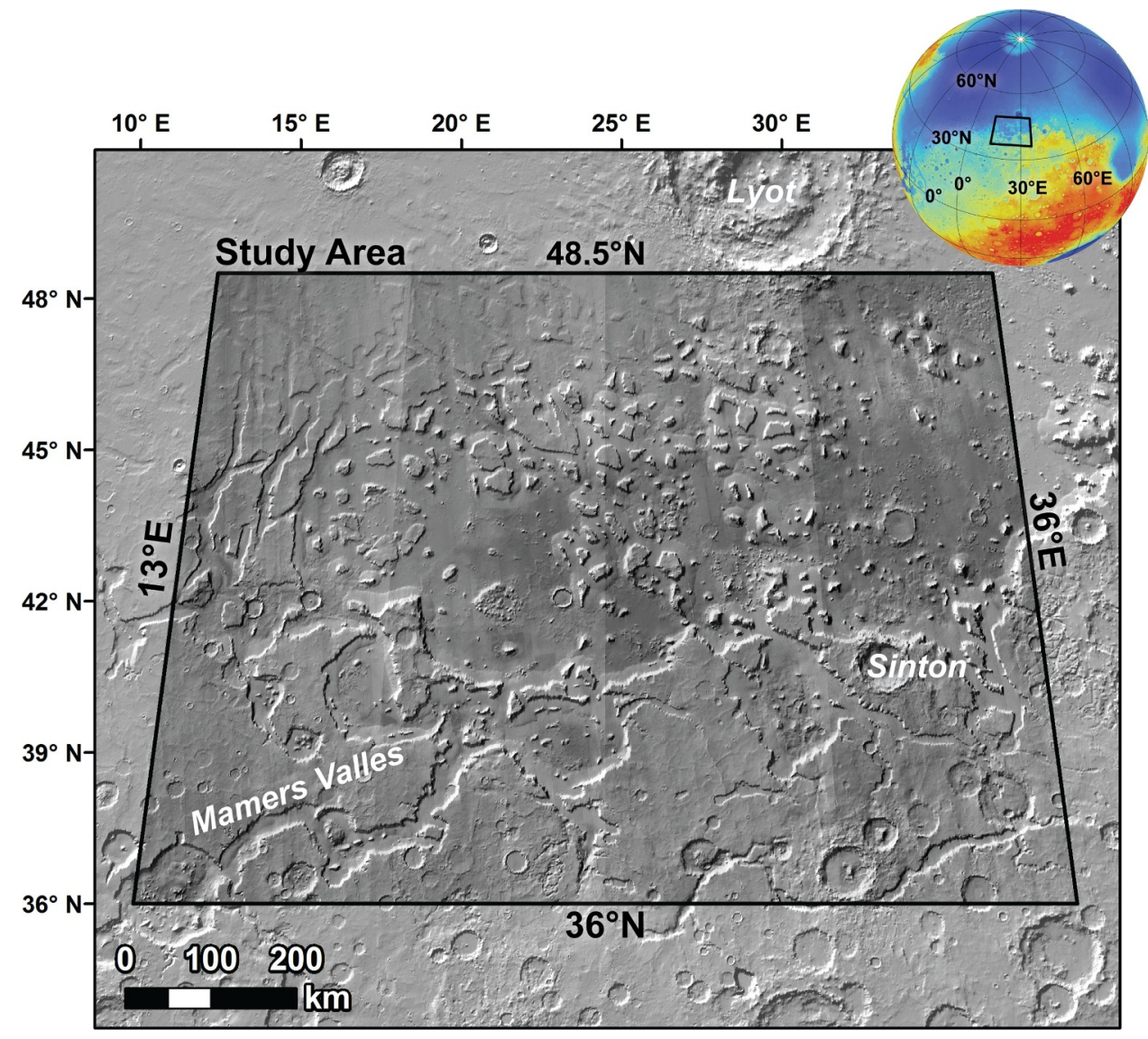

Fig. 2. Location of study area in Deuteronilus Mensae, Mars. Large map shows a tiled CTX image mosaic on MOLA hillshade. Inset hemispheric map is MOLA colored topography on MOLA hillshade. Inset box on the hemispheric map is the study area location. Sinusoidal projection centered at $24.5^{\circ} \mathrm{E}$. (For interpretation of the references to color in this figure legend, the reader is referred to the web version of this article.)

of the planet.

\section{Methods}

\subsection{Study area and unit mapping}

Our study area is the Deuteronilus Mensae region of Mars $\left(36-48.5^{\circ} \mathrm{N}, 13-36^{\circ} \mathrm{E}\right)$, which has been the subject of many prior analyses of ice-related Amazonian-aged features due to its high density of such features (Squyres, 1978; Li et al., 2005; Head et al., 2006a, 2006b; Morgan et al., 2009; van Gasselt et al., 2010; Berman et al., 2015; Baker and Head, 2015). It is located along the northern dichotomy boundary and includes a main dichotomy boundary escarpment and numerous isolated plateaus and massifs (Fig. 2).

To determine their complete extent and areal dimensions, all LDA, LVF, and CCF within the study area were mapped at 1:50,000 scale using a CTX image mosaic basemap within ESRI's ArcMap. A total of 568 CTX images were obtained from the Planetary Data System (PDS) (see list in Table S1) and were ingested into USGS ISIS software, individually calibrated, map-projected, and then mosaicked to create a nearly complete tiled mosaic of the entire study region at $6 \mathrm{~m} /$ pixel resolution (Fig. 2). We also used a MOLA gridded elevation basemap (PDS GEDR product) at 128 pixel per degree (ppd) for general topographic characterization.

Following prior mapping efforts, LDA, LVF, and CCF were recognized and mapped based on their distinguishing surface textures (Section 2.2), crater morphologies (Section 2.4) and convex-upward topographic signatures, as extensively described by previous work (e.g., Levy et al., 2009b; Baker et al., 2010; Head et al., 2010). We also mapped the plains surrounding the LDA, LVF, and CCF (Fig. 3) based on the recent mapping of a portion of the study area by Baker and Head (2015). As described by Baker and Head (2015) there are two major types of plains units in the region, Lower Plains and Upper Plains.
The Lower Plains consist of Hesperian-aged volcanic plains and younger Amazonian sedimentary deposits. The Upper Plains consists of a widespread Middle Amazonian-aged mantle unit that covers the Lower Plains and is most pervasive in the northern portion of the study area, thinning to the east. Baker and Head (2015) showed onlapping relationships between the mantle and LDA, suggesting that the mantle that forms the Upper Plains covers LDA, LVF, and CCF within the region. Remnant patches of the mantle within impact craters in the Lower Plains also suggest that the unit was once more widespread and has since been eroded back to its current extent.

\subsection{Surface texture mapping}

LDA, LVF, and CCF exhibit a range of surface textures that are thought to be shaped by a combination of resurfacing and aeolian processes, thermal contraction, and glacial flow (Mangold, 2003; Pierce and Crown, 2003; Levy et al., 2009b). These surface textures can therefore be used to infer the physical properties of the near-surface and the history of surface modification. The type and scale of surface textures are also important for interpreting SHARAD radar observations, as the radar signal is sensitive to topographic roughness at the $10-100 \mathrm{~m}$ length scale (Campbell et al., 2013; Petersen et al., 2016, 2017). We mapped LDA, LVF, and CCF surface textures using a grid-based approach (Ramsdale et al., 2017) at 1:25,000 scale using our CTX image mosaic and $5 \mathrm{~km} \times 5 \mathrm{~km}$ sampling cells spaced $10 \mathrm{~km}$ apart and completely contained within our mapped boundaries. A total of 1016 cells were visually examined for texture characteristics to create a coarseresolution map of regional-scale texture variations (Fig. 4). For each cell, we determined whether the following features were present at approximately $>10 \%$ areal coverage:

(1) Repeating stipple or mounded texture $(<100 \mathrm{~m}$ or $>100 \mathrm{~m}$ scale) (Fig. 5a-e): These consist of circular to elongate mounds of surface 


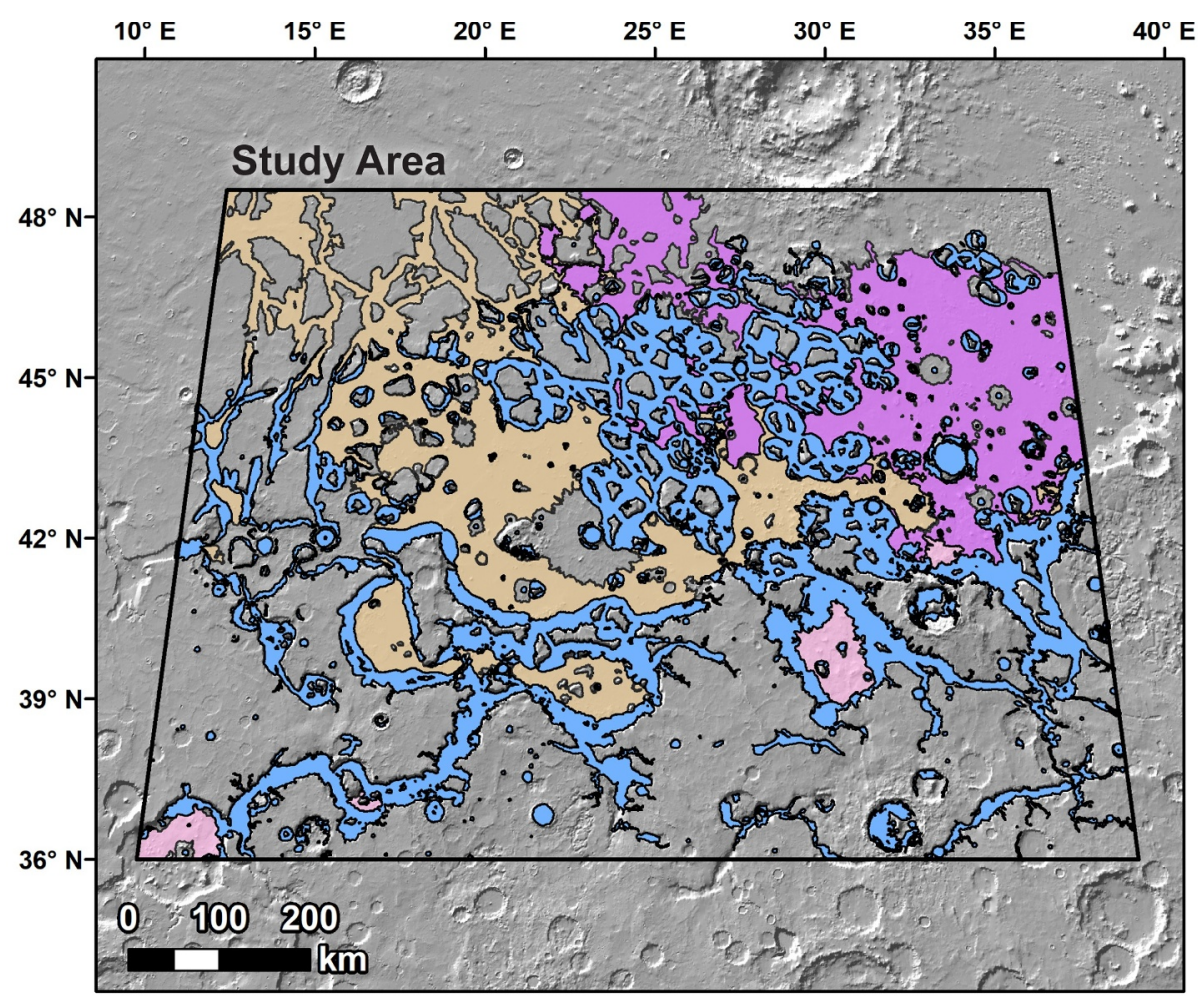

LDA, LVF, CCF $\square$ Upper Plains $\square$ Lower Plains $\square$ Undifferentiated Plains

Fig. 3. Generalized map of major geomorphic units within the study area.

material of similar size that are spaced at similar distances, repeating their pattern throughout the observation area.

(2) Lineations ( $<100 \mathrm{~m}$ or $>100 \mathrm{~m}$ scale) (Fig. $5 \mathrm{a}-\mathrm{d}$ ): Lineations are also common features of LDA, LVF, and CCF and are formed of complex patterns of linear and curvilinear ridges and furrows. These patterns are integrated with one another and resemble the

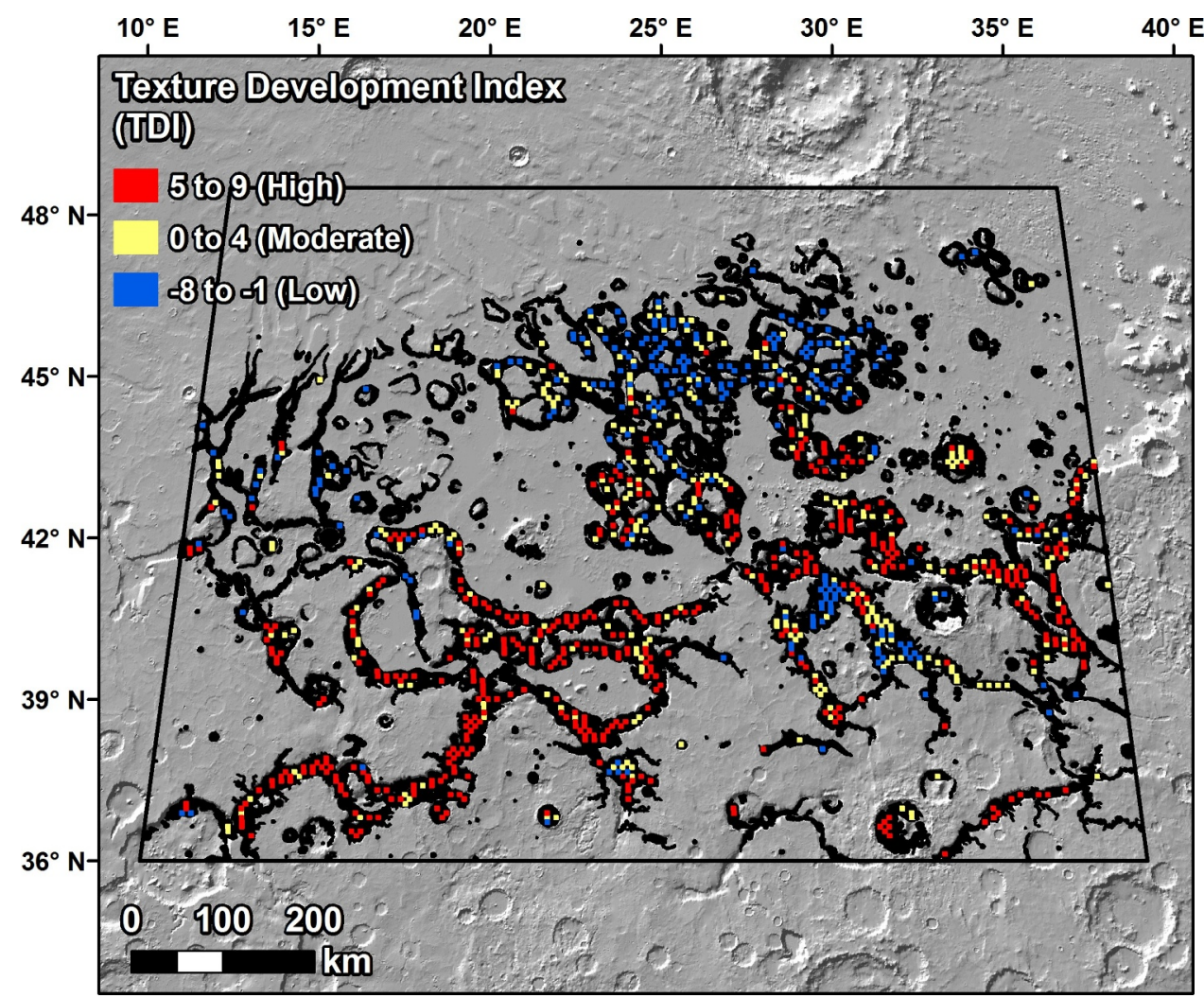

Fig. 4. Map of the distribution of LDA, LVF, and CCF surface textures, as represented by their Texture Development Index value (Section 2.2). Each symbol is a $5 \mathrm{~km}$ by $5 \mathrm{~km}$ cell separated by $10 \mathrm{~km}$ in longitude. 


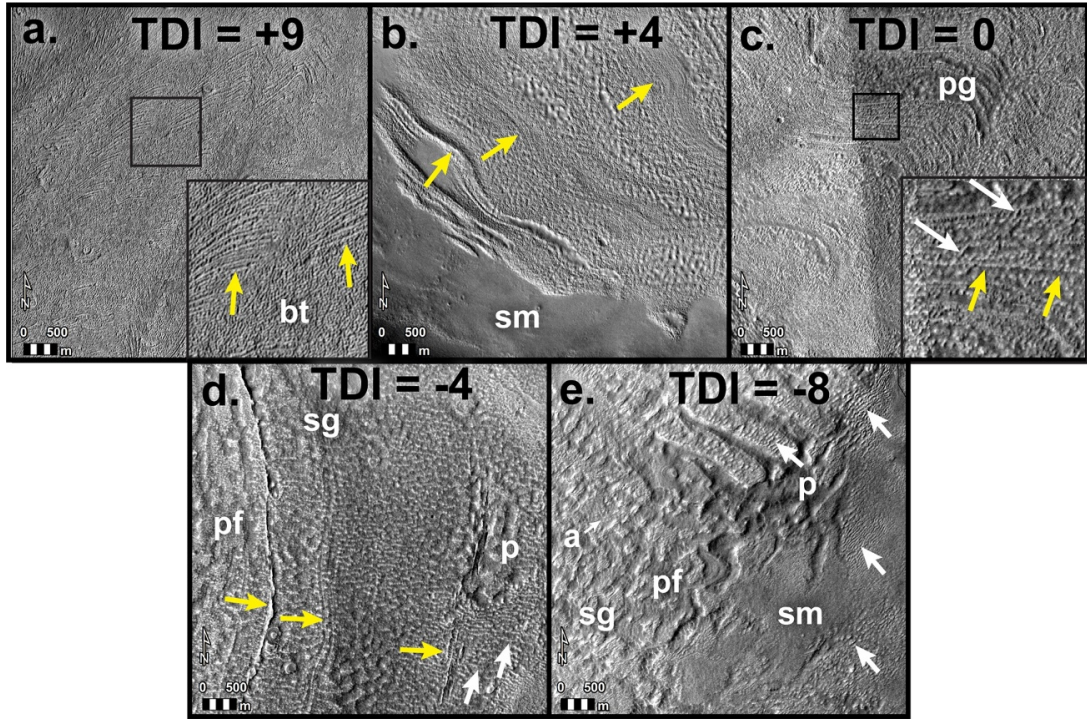

Fig. 5. Representative LDA, LVF, and CCF surface textures arranged based on their Texture Development Index (TDI) value. Images are from the CTX image mosaic described in the text. Abbreviated labels point to an example of one type of texture present: $\mathrm{bt}=$ "brain terrain", $\mathrm{sm}=$ smooth texture, $\mathrm{pg}=$ pits $>100 \mathrm{~m}$ in scale, $\mathrm{sg}=$ stippled texture $>100 \mathrm{~m}$ in scale, $\mathrm{pf}=$ plateau and furrow texture, $\mathrm{p}=$ pits $<100 \mathrm{~m}$ in scale, $\mathrm{a}=$ aeolian landform. (a) Type example with well-developed textures and "brain terrain". (b) Modified texture with smooth deposit in the lower left corner. Yellow arrows point to lineations interpreted to be due to glacial flow. (c) Modified texture with pitting and elongate stippled texture (white arrows) that is oblique to lineations (yellow arrows). (d) Heavily modified texture exhibiting a range of pitting, plateau and furrow texture and elongate stippled texture (white arrows). Yellow arrows point to lineations interpreted to be due to glacial flow. (e) The most highly modified terrain, exhibiting a wide range of textures. White arrows point to elongate ridges that resemble aeolian ripples. No lineations related to glacial flow are present. (For interpretation of the references to color in this figure legend, the reader is referred to the web version of this article.) glacial flow patterns of terrestrial glacial systems (Head et al., 2006a).

(3) Pits ( $<100 \mathrm{~m}$ or $>100 \mathrm{~m}$ scale) (Fig. $5 \mathrm{~d}$ and e): LDA, LVF, and CCF often have irregular pits that break the repeating stippled texture. These pits can be isolated to coalescent, or circular to elongate.

(4) Irregular plateau and furrow texture (multiple scales) (Fig. 5d and e): In some regions, irregular patches of near-surface material appear raised above the surrounding terrain and are often separated by similarly irregular depressions or lower flat, smooth areas. Some of these plateaus are etched with "brain terrain" patterns. This terrain is equivalent to the "ribbed" texture of Baker and Head (2015), which was interpreted to be formed mostly from disaggregation of mantle layers.

(5) Oriented stipple/mound texture (parallel or oblique to lineations) (Fig. 5c-e): Elongated stippled texture often appears aligned parallel with observed lineations (or inferred, downslope flow direction) or occur at oblique angles to lineations or inferred flow direction.

(6) Aeolian ripples/sculpture (Fig. 5e): These are ripples or faceted textures that are commonly associated with surfaces modified by aeolian activity on Mars.

(7) Smooth texture (<6-m scale; below CTX resolution) (Fig. 5b and e): Especially near the LDA, LVF, and CCF headwalls, textures below the 6-m spatial resolution of CTX appear smooth in the images. This smoothing is most commonly interpreted as a surface covering of dust or fine sediment, or could be areas of undeveloped textures or enhanced induration.

(8) "Brain terrain" (typically at the $10 \mathrm{~s}$ of meters scale) (Fig. 5a): This sub-type of "stipple or mounded terrain" is unique and common to LDA, LVF, and CCF. As the name implies, it has a brain-like texture of irregular, folding ridges and mounds (Levy et al., 2009b).

A well-developed type example of an LDA, LVF, or CCF surface (Fig. 5a) has a combination of the above textures, including: repeating stipple or mounded texture $<100 \mathrm{~m}$ that is not preferentially elongated in a specific direction, lineations at all scales, some pitting at $<100 \mathrm{~m}$ scale, no irregular plateau and furrow texture, stipple texture oriented with (not oblique to) lineations, no smooth surface covering, and "brain terrain" texture. To investigate the variability of surface textures in the region relative to this type example, we calculated a Texture Development Index (TDI) value for each mapping cell, as shown in Fig. 4. For each texture identified within the cell, we assigned a value of positive one to those characteristics of the type example. A value of negative one was assigned to those uncharacteristic of the type example, including aeolian erosion and absence of lineations or "brain terrain". Since terrains of all types have pits $<100 \mathrm{~m}$, we did not include these in the calculation of TDI. Table 1 lists the number assignments for each texture. We then summed all of the assigned values to determine the TDI. An observation cell with a TDI of +9 therefore has all of the texture characteristics of the type example, and a TDI of -9 has none of the characteristics. Intermediate values have different textures that are both characteristic and uncharacteristic of the type example (Fig. 5).

\subsection{Thermal inertia}

Thermal inertia can be used to make inferences on the grain size and the consolidated nature of the top centimeters of the surface. Values for thermal inertia (in "thermal inertia units", or tiu, $\mathrm{J} \mathrm{m}^{-2} \mathrm{~K}^{-1} \mathrm{~s}^{-1 / 2}$ ) have been calculated globally from observations by the Mars Global Surveyor (MGS) Thermal Emission Spectrometer (TES) instrument (Christensen et al., 2001) and the Thermal Emission Imaging Spectrometer (THEMIS) onboard Mars Odyssey (Christensen et al., 2003). Previous work on LDA and LVF elsewhere on Mars, including the southern highlands, has suggested some connection between TES and THEMIS thermal inertia and surface materials such as the presence of

Table 1.

Identified textures and assigned values for calculation of the Texture Development Index (TDI).

\begin{tabular}{lll}
\hline \multirow{2}{*}{ Texture } & \multicolumn{2}{l}{ Assigned value } \\
\cline { 2 - 3 } & Yes & No \\
\hline Reom Scale & & \\
Repeating stipple or mounded texture & $+1^{*}$ & -1 \\
Lineations & +1 & -1 \\
Pits & 0 & 0 \\
$>100 m$ Scale & & \\
Repeating stipple or mounded texture & -1 & 0 \\
Lineations & 0 & 0 \\
Pits & -1 & +1 \\
Various scales & & -1 \\
Irregular plateau and furrow texture & -1 & -1 \\
Stipple/mound texture oriented with flow & +1 & +1 \\
Stipple/mound texture oriented oblique to flow & -1 & +1 \\
Aeolian ripples/sculpture & -1 & +1 \\
Smooth texture & -1 & -1 \\
"Brain terrain" & +1 & \\
\hline
\end{tabular}

NA: Not applicable

*Elongate stipple or mounded texture was assigned a value of -1 . 
dust or mantle or formation mechanism (e.g., rock glacier with a high internal rock content versus debris-covered glacier with a core of nearly pure glacial ice; see Haeberli et al., 2006) (Chuang and Crown, 2005; Piatek et al., 2008, 2009). However, the cause of these variations were largely unclear in part due to an inability to verify correlated surface characteristics based on high-resolution datasets.

Here, we use the $3 \mathrm{~km} /$ pixel global TES-derived nighttime thermal inertia map produced by Putzig and Mellon (2007) for regional characterization. A quantitative THEMIS thermal inertia mosaic data at $100 \mathrm{~m} /$ pixel resolution (Edwards et al., 2011) was used to spatially resolve smaller-scale variations in thermal inertia in select regions that might be tied to material or textural changes. The THEMIS mosaic is available on the PDS Imaging Node Annex (THEMIS_TI_Mosaic_Qual_30N000E_100mpp) and methods used to create the mosaic are described in Edwards et al. (2011). Briefly, they used the methods of Fergason et al. (2006) to determine thermal inertia for each THEMIS image and then mosaicked all images together by ordering the highestquality images at the top and preserving the absolute values of thermal inertia derived for each visible THEMIS frame. Individual images have an uncertainty in derived thermal inertia of $\sim 10-15 \%$ (Fergason et al., 2006). The uncertainty between multiple observations, however, is higher at $\sim 30 \%$ due to actual variations in the atmospheric and surface properties that may change between THEMIS observations. In our analysis of THEMIS thermal inertia, we therefore restricted comparisons between surface units to single THEMIS frames within the larger mosaic tile.

We also used HiRISE images $(25-50 \mathrm{~cm} /$ pixel), where available, to assess the possible causes of the variations in thermal inertia. Specifically, we visually inspected images over representative areas for the presence of boulders $>1 \mathrm{~m}$ in size, textural differences, and smooth, dusty areas, which may affect thermal retention and dissipation in the top centimeters of the surface.

\subsection{Crater mapping}

Well-preserved impact craters formed within LDA, LVF, and CCF can be used to assess the potential effects of target properties such as material strength on crater formation. Examining a range of crater sizes, and hence depths of excavation and deformation, also provides information on how these target properties change with depth. For example, on the Moon, differences in the strength of surface regolith and mare lavas are thought to have produced terraced, mounded, and flatfloored interior morphologies that systematically change with the size of the crater. This size-morphology trend was observed for craters $\lesssim 250 \mathrm{~m}$ in diameter and has been used to estimate the thickness of nearsurface regolith on the Moon to a few meters (Quaide and Oberbeck, 1968; Bart et al., 2011). On Mars, terraced or concentric craters in Amazonis Planitia are thought to result from differences in ice content of near-surface materials (Bramson et al., 2015; Viola et al., 2015). In addition to strength contrasts in materials, differences in amount of sublimation of subsurface ice and erosion may account for these features on Mars.

Likewise, we examined well-preserved craters on LDA, LVF, and CCF (Fig. 6, Appendix A) to assess possible morphological changes with size and to examine evidence of layering and physical characteristics of materials within the crater walls and ejecta. Well-preserved craters within LDA, LVF, and CCF are recognized by their characteristically sharp rim-crests that are typically circular in planform (Fig. 6). Their interiors also lack significant interior fill. Thus, these craters have not been substantially modified by post-impact processes and therefore can be used to estimate the shape of the crater that formed shortly after impact. Using these criteria, all well-preserved craters $\geq 75 \mathrm{~m}$ in diameter on LDA, LVF, and CCF $(N n=1408)$ were systematically mapped from the CTX mosaic using the CraterTools extension in ArcMap (Kneissl et al., 2011). See Table S2 for the locations of these craters. Circle-fits using the CraterTools three-point method were visually made to each crater's rim crest, which provided measurements of their rimcrest diameters $\left(D_{\mathrm{r}}\right)$ (Fig. A1).

Many other crater morphologies also occur that provide a rich dataset for assessing near-surface structure and modification history. We separately classified and mapped all additional crater types $\geq 125 \mathrm{~m}$ in diameter across the study area, for a total of 16,457 craters. We report on our observations and interpretations of this dataset in a companion paper (Baker and Carter, 2019). Briefly, we identified several new classifications of craters, showing small differences in median diameters between types and variations in spatial density that appear to be correlated with surface texture development.

\subsection{Crater depths}

Understanding the depth of well-preserved craters is important for assessing their degree of modification relative to other craters on Mars and for estimating the depth of origin of wall and ejecta materials. We measured the depths of well-preserved craters $>250 \mathrm{~m}$ in diameter ( $n=64$ ) using two methods. See Appendix A for detailed methods and Tables S3 and S4 for measurement data. First, we calculated the difference in the average rim-crest height and minimum floor elevation determined from CTX DEMs generated using CTX stereo pairs and Ames Stereo Pipeline tools. The depths of 25 craters were analyzed this way; the craters were selected based on the availability of CTX stereo pairs and the presence of nearby SHARAD tracks that could confirm the detection of a basal reflector and therefore interpretation of glacial ice at depth (see Sections 2.8.2 and 4.3). Second, we measured depths based on shadow measurements from CTX images and HiRISE images with parameters favorable for making such measurements (Appendix A). A total of 61 CTX images and three HiRISE images were used in the measurement of 56 craters, which were selected based on the availability of images. Among those measured craters, 17 had measurements from both shadows and CTX DEMs, providing a useful comparison between the two methods.

\subsection{Crater wall characteristics}

A total of 101 of the mapped well-preserved craters were imaged by HiRISE, allowing detailed assessments to be made of their wall and interior characteristics (see Table S5 for observations). The craters in this sample ranged in diameter from $75 \mathrm{~m}$ to $465 \mathrm{~m}$, (average of $145 \mathrm{~m}$ ), permitting examination of the properties of supraglacial debris from the surface to a maximum depth of 15 to $93 \mathrm{~m}$, assuming $d=0.2 D_{\mathrm{r}}$ (Section 3.4). For each crater, we made visual observations of the presence or absence of layering, polygons, slump materials, and boulder abundance. We visually classified their wall boulder abundance on a scale of 0 to 5 (Fig. 6a-f). A value of zero had no visible boulders at the $>1 \mathrm{~m}$ scale of HiRISE; a value of 1 had less than $\sim 10$ perceptible boulders; 2 had several dozen boulders concentrated in portions of the wall but still dominated by finer-grained material; 3 had more widespread boulders throughout the entire wall but still largely dominated by finer-grained materials; 4 , boulders were pervasive and larger in scale; 5 had very large boulders meters across and/or were completely dominated by boulders.

\subsection{Crater size-frequency distribution}

It is well known that craters on Mars and planetary bodies degrade at rates that are dependent on many factors, including crater size, target properties, and erosional and depositional processes (e.g., Hartmann, 1971; Craddock et al., 1997; Hartmann and Neukum, 2001). Depending on these factors, craters of a certain degradation class will have a characteristic survival timescale before they are modified into more degraded types, which can be evaluated using crater size-frequency distributions and comparing these to established isochrons (Hartmann and Neukum, 2001). We estimated the survival timescale of well- 


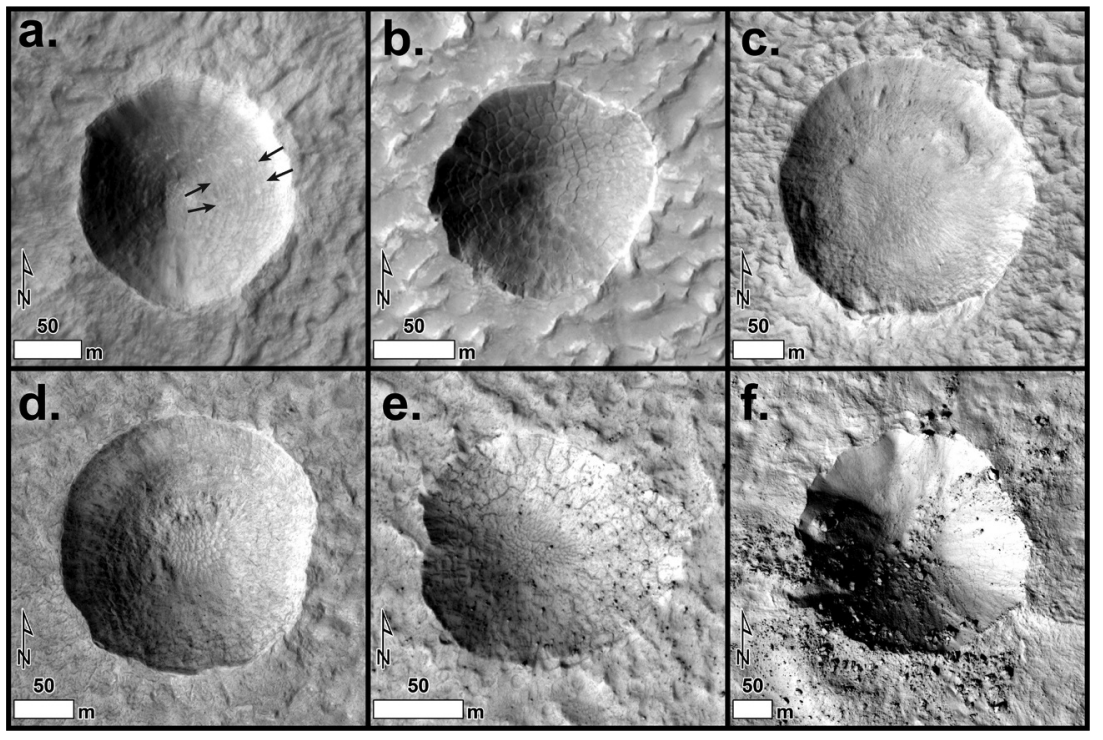

Fig. 6. Images of well-preserved craters showing the range of boulder concentrations in their interiors (see Section 2.6). (a) Boulder concentration value $(\mathrm{BCV})=0$; crater centered at $38.17^{\circ} \mathrm{N}, \quad 17.94^{\circ} \mathrm{E}$, diameter $166 \mathrm{~m}$, HiRISE image ESP_026704_2184_RED. Arrows point possible to fine layering at the top and bottom of the crater wall, with additional layers in between. (b) $\mathrm{BCV}=1$; centered at $43.74^{\circ} \mathrm{N}, 24.91^{\circ} \mathrm{E}$, diameter $138 \mathrm{~m}$, HiRISE PSP_009733_2240_RED. (c) $\mathrm{BCV}=2$; centered at $39.97^{\circ} \mathrm{N}, 20.90^{\circ} \mathrm{E}$, diameter $259 \mathrm{~m}$, HiRISE PSP_007716_2200_RED. (d) BCV $=3$; centered at $42.33^{\circ} \mathrm{N}$, $18.36^{\circ} \mathrm{E}$, diameter $225 \mathrm{~m}$, HiRISE ESP_015944_2225_RED. (e) $\mathrm{BCV}=4$; centered at $45.32^{\circ} \mathrm{N}, 19.65^{\circ} \mathrm{E}$, diameter $140 \mathrm{~m}$, HiRISE PSP_006714_2255_RED, (f) $\mathrm{BCV}=5$; centered at $38.16^{\circ} \mathrm{N}, \quad 28.84^{\circ} \mathrm{E}, \quad$ diameter $293 \mathrm{~m}, \quad$ HiRISE PSP_006661_2185_RED. Projections are Sinusoidal centered on the crater.

preserved craters by plotting their crater size-frequency distribution (Fig. 17 and Section 3.6) as an incremental plot (Hartmann, 2005). A best-fit to the crater distribution was determined by minimizing the sum of squared residuals between the binned data and modeled isochrons. The residuals were weighted as the inverse of the square root of the number of samples in the bin.

\subsection{SHARAD radar data analysis}

\subsubsection{Near-surface reflectors}

If the total supraglacial debris thickness or internal layering is on the order of tens of meters, then it is possible that the interface with the glacial ice or between layers can be detected with MRO SHARAD radar data (Seu et al., 2007). The SHARAD instrument operates at a center frequency of $20 \mathrm{MHz}$, with a vertical resolution of $15 \mathrm{~m}$ in free space, scaling as $1 / \sqrt{ } \varepsilon$ in geologic materials (where $\varepsilon$ is the real permittivity or dielectric constant). Its spatial resolution is $0.3-0.6 \mathrm{~km}$ along track and 3-6 km cross track. SHARAD radar data are analyzed as radargrams (Fig. 7a), which show along-track distance in the x-direction and twoway time delay in the y-direction. Returns from off-nadir topographic facets, or "clutter," can occur at late time-delays that may be mistaken for real subsurface returns in the radargrams. This clutter can been simulated and displayed as "cluttergrams" (Fig. 7b) which can be used to confirm real subsurface reflectors. Clutter and "sidelobes" paralleling the bright surface return often make confident recognition of nearsurface reflections challenging (Fig. 7c and d) (e.g., Putzig et al., 2014). Sidelobes result from range compression of the SHARAD radar signal during processing, and can be difficult to suppress. For the PDS US Team SHARAD RDR products used here, the first and second sidelobes are expected at time delays and powers of $0.24 \mu \mathrm{s},-20 \mathrm{~dB}$ and at $0.42 \mu \mathrm{s},-34 \mathrm{~dB}$, respectively (Putzig et al., 2014). It is therefore desirable to have reflectors that are either greater in power than the sidelobes or occur at different time delays; both conditions are ideal.

We surveyed 648 SHARAD nightside radargrams covering the region in search for near-surface reflectors. All radargrams were US Team SHARAD observations from December 2006 to April 2015 and available from the PDS (see Table S6 for a listing of analyzed SHARAD observations). Each radargram was prepared by automatically overlaying the mapped boundaries of the LDA, LVF, and CCF (Fig. 3) onto the radargrams (Fig. 7a). The portions of each radargram covering LDA, LVF, or CCF were visually inspected to identify candidate near-surface reflectors. The radargrams were then compared with clutter simulations (Fig. 7b) (Choudhary et al., 2016) made available by the SHARAD team (Putzig et al., 2016) to reject the candidate reflectors if they were likely due to off-nadir surface returns. We also rejected the reflectors if they appeared to be consistent with expected sidelobes, i.e., if they were parallel to each other and the surface return and occurred at times delays of $0.24 \mu$ s or $0.42 \mu$ s (Fig. $7 c$ and d).

\subsubsection{Basal reflectors}

Strong radar reflectors associated with LDA at time-delays consistent with the inferred base of the glaciers (Fig. 7a) suggest relatively pure ice at these locations (Holt et al., 2008; Plaut et al., 2009). We identified the presence of similar basal reflectors for a selection of LDA and LVF in which occur 48 well-preserved craters $>250 \mathrm{~m}$ in diameter. The presence of a basal reflector is strong evidence for the presence of subsurface ice and can be used to assess the possible influence of ice on the formation and modification of these craters. The nearest SHARAD track to each crater was selected for analysis, which, on average, was found to be within $1.1 \mathrm{~km}$ from the center of the crater. Only the largest craters from our database were chosen due to the improved ability to discriminate morphologic details at these sizes based on images and DEMs and the relatively large spatial footprint of SHARAD. Methods used for determining LDA and LVF thickness from SHARAD radargrams are provided in Appendix B and Table S7 provides the measurement data.

\section{Results}

\subsection{Distribution of LDA, LVF, and CCF and surface textures}

LDA, LVF, and CCF cover $166,034 \mathrm{~km}^{2}$ of area in the study region (Fig. 3) and show spatial patterns in surface textures (Fig. 4). In general, LDA, LVF, and CCF are found to originate at most slopes $>5^{\circ}$, including the walls of plateaus and massifs. While our mapped features are qualitatively similar to a recent global map of LDA, LVF, and CCF by Levy et al. (2014), our mapping results are $21 \%$ greater in area within the study region [Levy et al. (2014) mapped $134,782 \mathrm{~km}^{2}$ of LDA, LVF, and CCF in the study region]. This difference is most likely due to our use of full resolution CTX images at $\sim 6 \mathrm{~m}$ /pixel; Levy et al. (2014) mapped LDA, LVF, and CCF using a global CTX image mosaic at three times coarser resolution ( $18 \mathrm{~m} /$ pixel). Due to our use of a higher spatial resolution mosaic, we were able to better resolve LDA, LVF, and CCF surface textures and contacts more precisely and confidently. We also included glacial material, such as glacial-like forms (Souness et al., 2012), contained within small alcoves in the headwall regions, which may have been the accumulation zones for the main bodies of LDA and LVF (Head et al., 2010) 

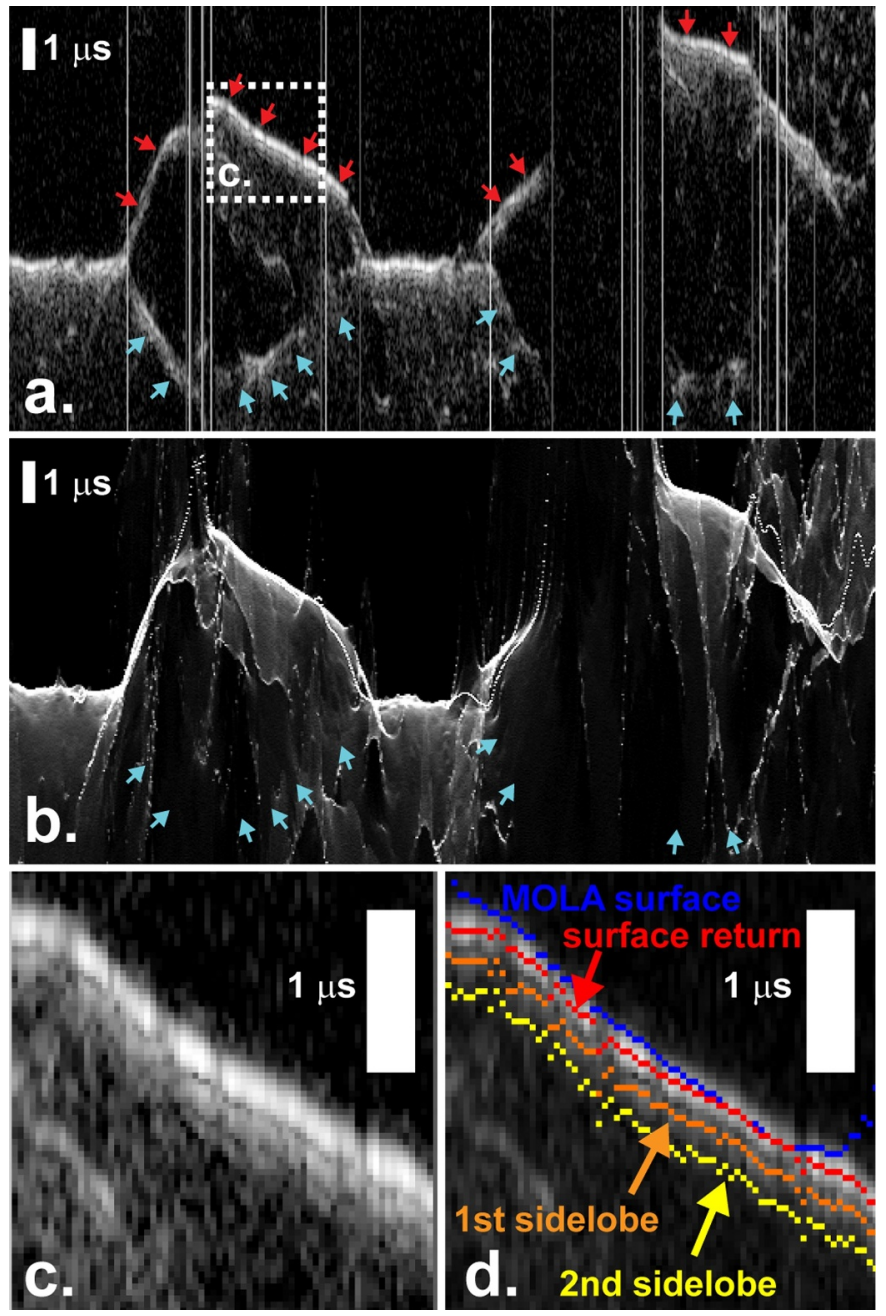

Fig. 7. Identification of surface and subsurface returns from SHARAD radar observations. (a) Portion of SHARAD radargram (00683902; radar columns 843 to 1406) with the surface returns (downward red arrows) and basal reflections (upward blue arrows) of LDAs identified. Vertical lines give the boundaries of LDAs as mapped in Fig. 3. Inset box gives the location of panels $\mathrm{c}$ and d. (b) Clutter simulation ("cluttergram") showing modeled off-nadir surface returns. The basal reflectors (blue arrows) are not present, confirming that they represent real subsurface reflectors. (c) Close-up of the surface returns of an LDA, with outlines of the predicted MOLA surface, the surface return, and first and second sidelobes shown in (d).

To qualitatively assess spatial variations in LDA, LVF, and CCF textures, we group and display their texture development index (TDI) values (Section 2.2) into "low" ( -8 to -1 ), "moderate" (0 to 4$)$, and "high" (5 to 9) based on the Jenks natural breaks method (Fig. 4), which determines classifications by maximizing the magnitude of the difference in parameter values between a specified number of groups (de Smith et al., 2015). Broadly, there is a clustering of low TDI values in the northern portion of the study area and high TDI in the south. Calculation of the Global Moran's I statistic for the spatial distribution of TDI values, which tests the null hypothesis that the features are spatially random, yields a $p$-value of $<0.01$ and Moran's I Index value of 0.5 . Based on these results, this test statistic strongly suggests that the spatial distribution of TDI values is more clustered than would be expected if the underlying spatial process was random.

The spatial clustering in TDI has a possible dependence on both latitude and local, catchment-scale variations in geology or micro-climate. TDI values qualitatively appear to decrease with increasing latitude (Fig. 4). A plot of the mean TDI in two-degree latitude bins (Fig. 8a) shows a weak decrease in TDI with latitude from $36^{\circ} \mathrm{N}$ to $43^{\circ} \mathrm{N}$ and a sharp decrease in TDI at $44^{\circ} \mathrm{N}$ that is more statistically significant. These areas north of $44^{\circ} \mathrm{N}$ have more abundant plateau and furrow textures (Fig. 5e), which Baker and Head (2015) interpret to be related to greater preservation of broad, continuous patches of mantle at these locations. However, there are also pockets of low to moderate TDIs in the southern portion of the study area that are not associated with plateau and furrow texture and may result from local characteristics such as enhanced erodibility of surface debris or topographically enhanced wind abrasion and sediment transport. To the west of the large Amazonian-aged Sinton crater (Fig. 2), the surface has well-developed stipple texture but lacks lineations and "brain terrain" (Fig. 9a). Nearby, prominent elongate ridges cross-cut lineations, appearing to have been sculpted by aeolian erosion and transport (Fig. 9b). This area also corresponds to a region of low thermal inertia (Fig. 10a) and is also nearby Sinton crater. The unique surface textures here could therefore be related to the material properties surrounding Sinton crater, such as more friable ejecta, or wind-transported fines that are deposited across the region (Morgan and Head, 2009). We further discuss the possible processes responsible for LDA, LVF, and CCF texture development and spatial variations in Section 4.4.

\subsection{Thermal inertia and boulders}

In general, LDA, LVF, and CCF have lower TES thermal inertia (peak near 170 tiu) than the surrounding plains (more uniformly distributed between 120 to 320 tiu) (Fig. 10b). The LDA, LVF, and CCF values are low to moderate in context of martian global values (Putzig and Mellon, 2007), and can be consistent with a number a physical characteristics, including loose, fine particles such as dust and very few rocks to coarser loose particles, crusted fines, and or some scattered rocks. The thermal inertia values are also generally on the low end of the range for LDA in the Tempe/Mareotis region (Chuang and Crown, 2005), where values ranging from 69 to 350 tiu were observed from TES thermal inertia maps of Mellon et al. (2002). Chuang and Crown (2005) suggested that variability in the TES thermal inertia could be due to a variety of factors, including differences in the amount of rocks and fines and duricrusts or aggregates of fine particles at the surface. They also noted the lower thermal inertia and inferred reduced rock abundance of LDA compared with the surrounding plains. However, HiRISE images were not available at the time to confirm spatial correlations with large boulder abundance.

The higher-resolution $(100 \mathrm{~m} /$ pixel) quantitative maps of THEMIS thermal inertia also show the relatively sharp contrast in thermal inertia between LDA ( $<200$ tiu) and the plains ( $>200$ tiu) (Fig. 11a). A HiRISE image straddling a representative contact (Fig. 11a) suggests that the presence of mantle material and grain size differences in the upper few centimeters, including surface boulder abundance, is a major source of the variation in thermal inertia. The surface of the LDA shows a typical stippled pattern formed from high-albedo mantle that generally lacks boulders ( 180-190 tiu; Fig. 11b). Irregular to circular plateaus of mantle are also observed that are raised above the surrounding terrain. The topographic lows in between mantle ridges appear smoother and lower in albedo, similar to dust-covered regions elsewhere on Mars, and suggest that trapping of fines by LDA, LVF, and CCF textures could further contribute to a reduction in their thermal inertia, as previously suggested by Chuang and Crown (2005). The terminus of the LDA shows a reduction in the relief of the mantle textures and an increase in boulder abundance and thermal inertia downslope toward the plains (Fig. 11c and d). A representative region of plains (Fig. 11d) shows an abundance of boulders and thermal inertia of $\sim 320$ tiu, or $\sim 140-130$ tiu higher than the LDA surface (Fig. 11b). Patches of mantle similar to those occurring on the LDA are also found within craters $<500 \mathrm{~m}$ in size within the plains (Fig. 11e). Like the surfaces of LDA, the mantle patches lack boulders and are higher albedo than the rocky walls of the craters, which are formed of plains material.

There are also large spatial heterogeneities in thermal inertia within 
a.

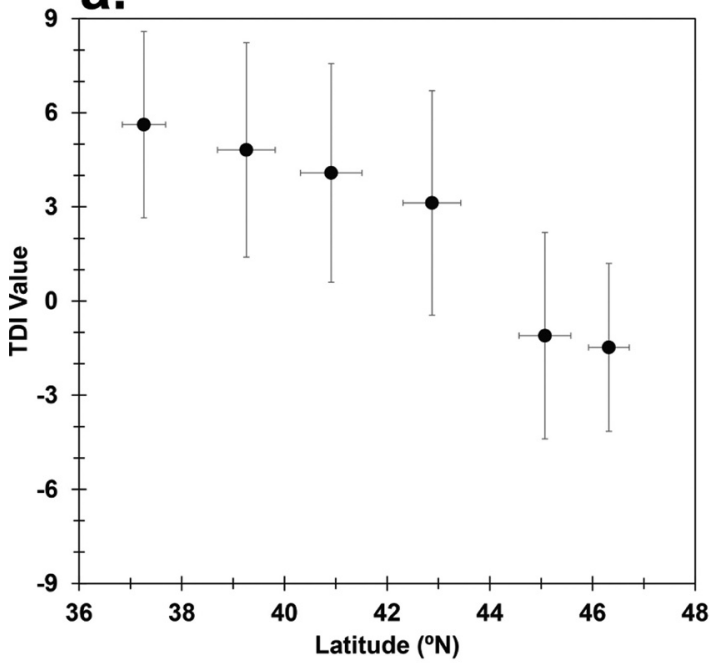

b.

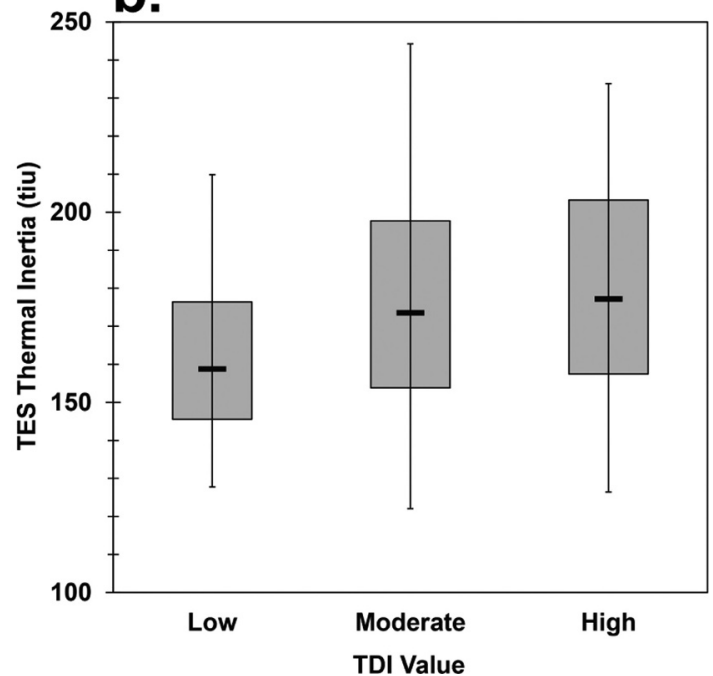

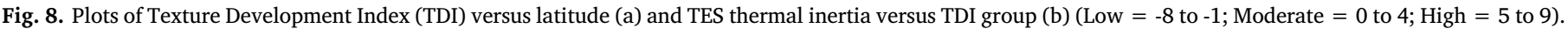

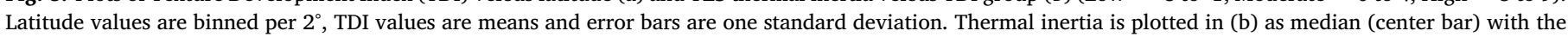
interquartile range (box) and 5th and 95th percentiles (error bars) for each TDI group.

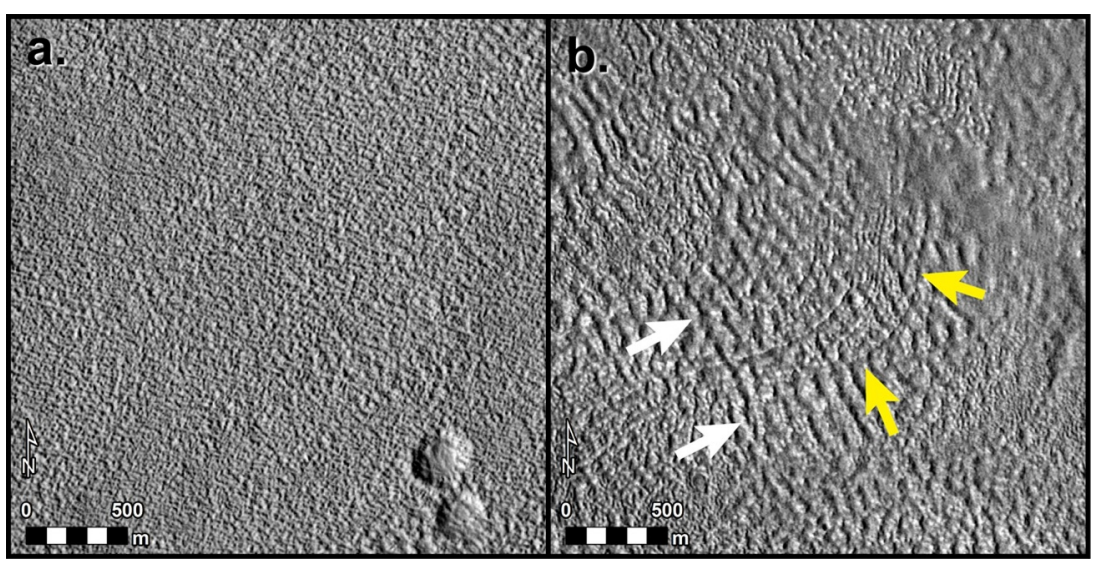

Fig. 9. Examples of textures with low to moderate TDI on LDA in the southern portion of the study area. (a) Stippled texture at $<100 \mathrm{~m}$ scale; no lineations interpreted to be due to glacial flow are observed. CTX image mosaic centered at $40.54^{\circ} \mathrm{N}$, $29.93^{\circ} \mathrm{E}$. (b) Elongate ridges, possibly formed by aeolian activity (white arrows), cross-cutting lineations interpreted to be due to glacial flow (yellow arrows). CTX image mosaic centered at $40.45^{\circ} \mathrm{N}, 27.72^{\circ} \mathrm{E}$. (For interpretation of the references to color in this figure legend, the reader is referred to the web version of this article.)

the mapped boundaries of LDA, LVF, and CCF. Our observations indicate that many of the variations in LDA, LVF, and CCF thermal inertia are spatially associated with variations in near-surface abundance of boulders and presence of mantle coverings. Observed boulders are often concentrated in flow-like bands and broad regions at the termini of LDA and resemble terrestrial glacial landforms (Fig. 12). In CTX and other visible images, LDA often exhibit low albedo bands that parallel topographic flow-like lineations (Fig. 12a). THEMIS data reveal that these low albedo bands are also correlated with relatively high thermal inertia (Fig. 12b). In one representative location, debris bands with thermal inertia of $\sim 250$ tiu originate at the rocky headwalls (thermal inertia generally $>280 \mathrm{tiu}$ ), parallel the topographic gradient, and broaden into a concentrated region of high thermal inertia values ( $\sim 240-290$ tiu) near the LDA terminus (Fig. 12b). A HiRISE image (Fig. 12e) shows that the bands and terminus have few prominent mantle ridges and a higher concentration of boulders $>1 \mathrm{~m}$ in size compared with the surrounding terrain, which has prominent mantle ridges, no visible boulders, and lower thermal inertia $(\sim 180$ tiu; Fig. 12c). Areas of LDA with intermediate thermal inertia values show a mixture of mantle ridges with lower relief and scattered boulders (Fig. 12d). A thermal inertia value of $\sim 250$ tiu for the debris bands and termini, which is at the low end for rocky materials on Mars (Nowicki and Christensen, 2007), indicates that there is also a large component of fine-grained sediment, which may due to trapping of dust or the presence of remnant mantle material between larger boulders. This is consistent with the HiRISE images, which show a mixture of smoother, high-albedo patches of sediment between concentrated fields of boulders (Figs. 12e and 13e).

The qualitative correspondence between thermal inertia and boulder abundance suggests that THEMIS thermal inertia can be a useful tool for estimating the fraction of LDA surfaces dominated by mantle or exposed surface boulders over areas much larger than a typical HiRISE footprint. While more quantitative methods should be explored (e.g., Nowicki and Christensen, 2007), as an initial investigation, we assume that thermal inertia can be used as a first-order proxy for relative variations in mantle and boulder abundance and attempt to estimate the relative fractions of LDA surfaces dominated by mantle, boulders, or intermediate mixture of the two. We expanded the region in Fig. 12 to the north and south so that the investigated region was within a single THEMIS frame (Fig. 13a), and then divided LDA surfaces into three classes based on their thermal inertia values (Fig. 13b). Division boundaries at 211 tiu and 234 tiu were determined using the Jenks natural breaks methods from the distribution of thermal inertias, as used for the TDI classification (Section 3.1). Qualitative examination of two available HiRISE images over the classified areas shows that the classification works reasonably well at predicting low, intermediate, and high boulder regions. Like the sub-region in Fig. 12, other regions of "low" thermal inertia show minimal boulders and more prominent high-albedo mantle ridges (Fig. 13c). Like the debris bands in Fig. 12, regions of "high" thermal inertia show the highest 

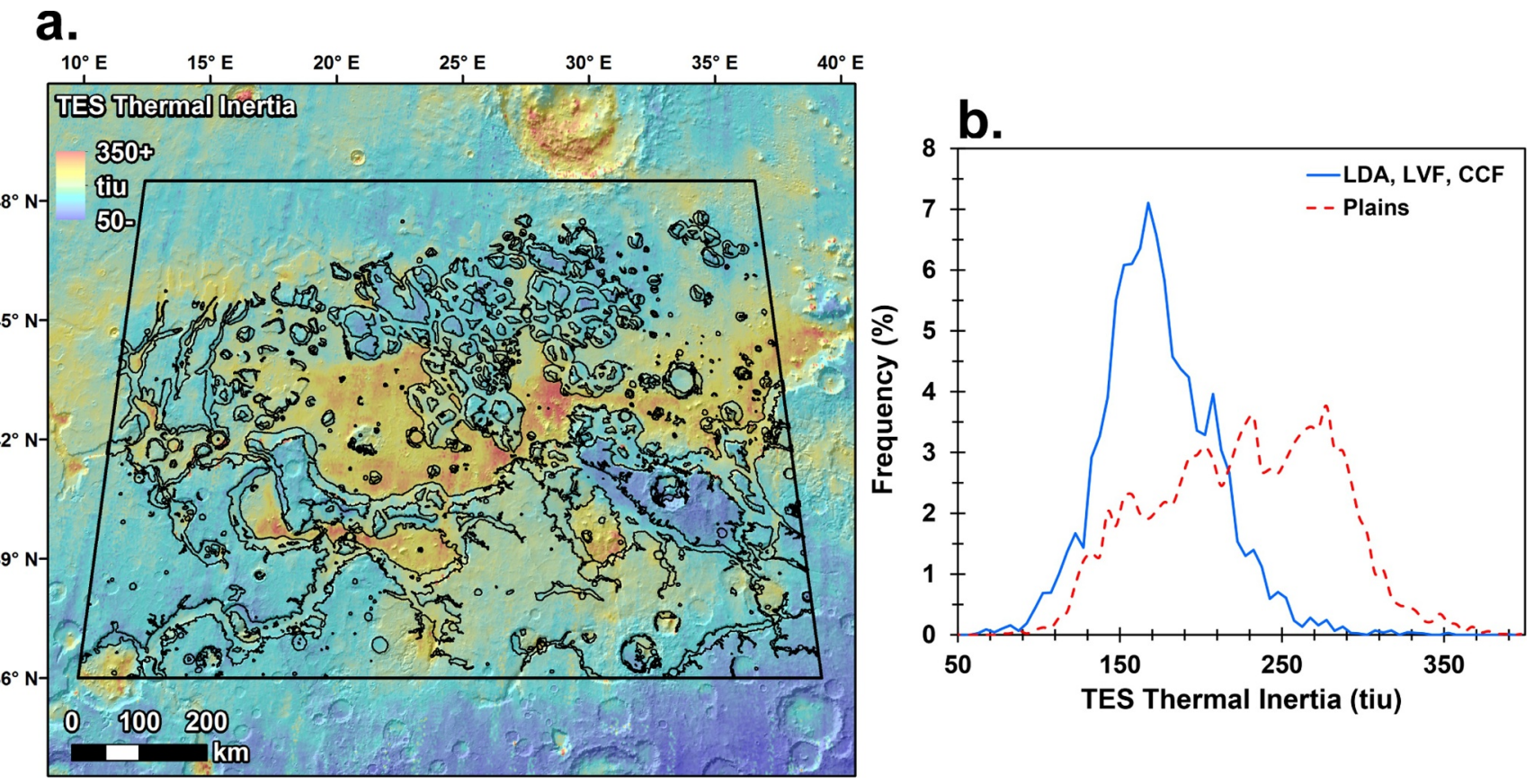

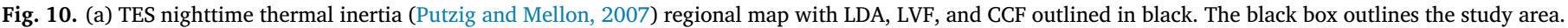

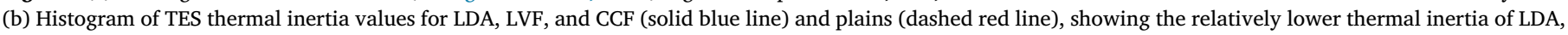
LVF, and CCF. See Fig. 3 for the spatial locations of the mapped units.

concentrations of boulders, a reduction in mantle terrain, and a lowering of albedo (Fig. 13e). This reduction in albedo is also observed in CTX images and is common to rock-rich areas across the martian surface (Nowicki and Christensen, 2007). Surfaces with the highest concentration of boulders appear to be focused within additional debris bands and at the termini of the LDA (Fig. 13a and b). This is consistent with terrestrial glaciers, where supraglacial debris generally thickens toward the terminus of the glacier as glacial flow transports rockfall material downslope away from the headwalls and ablation of ice liberates sediment (Benn and Evans, 1998, p. 243-247). Areas of "moderate" thermal inertia show intermediate mixtures of mantle ridges and boulders (Fig. 3d).

Assuming that the thermal inertia classification is tracking boulder abundance reasonably well, $18.8 \%$ of the LDA surfaces have "high" thermal inertia and are predicted to be boulder-rich, while $31.5 \%$ have "low" thermal inertia and are predicted to be covered by mantle with few to no boulders (Fig. 13b). The remaining $49.7 \%$ is predicted to have intermediate fractions of mantle and boulders. We have not fully considered possible variations in compaction, cementation, and fines at the surface that will affect the thermal inertia, so the classification should be considered as an approximation that should be verified by more rigorous quantitative methods. However, the strong qualitative correspondence with boulder abundance and mantle, as documented here (Figs. 12 and 13), suggests that relative variations in boulders and mantle are major drivers of the thermal inertia variations.

\subsection{Well-preserved craters and wall and ejecta characteristics}

Despite their "fresh" appearance, only 3\% of the 1408 well-preserved craters $\geq 75 \mathrm{~m}$ in size $(n=41)$ exhibit any textural or albedo evidence of a complete or partial ejecta layer, despite the observations pointing to rockfall as a significant component of supraglacial debris. We also find that the walls of the craters are generally boulder-poor and lack visible layers. Further, no trend in boulder concentration with

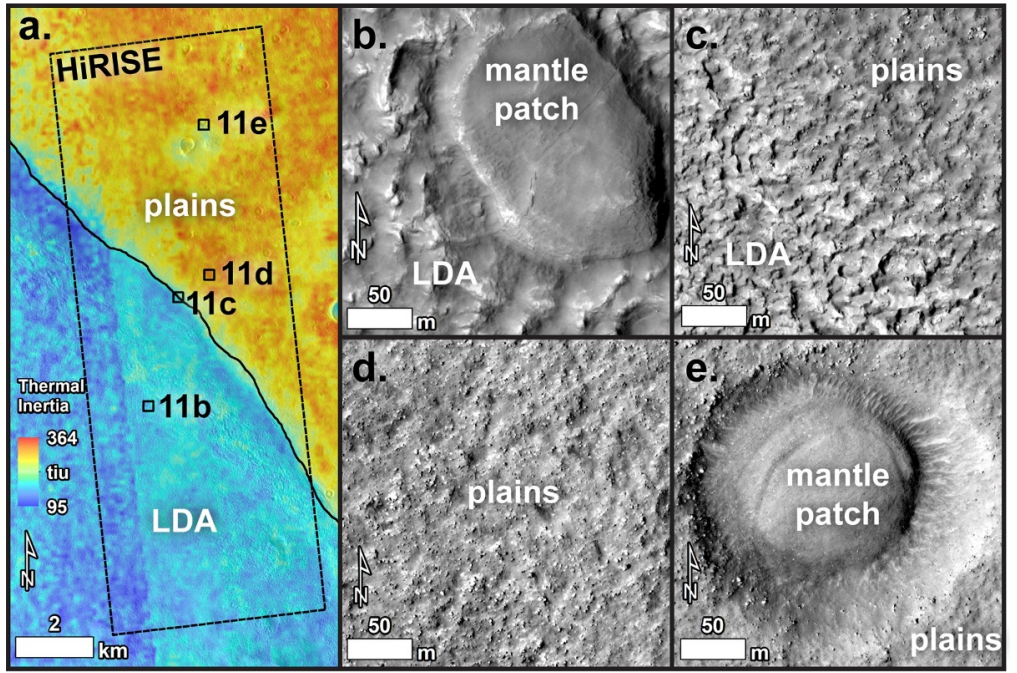

Fig. 11. Thermophysical properties across the contact between an LDA and surrounding plains. (a) Quantitative THEMIS thermal inertia map (Edwards et al., 2011), showing relative differences in thermal inertia. Location is centered at $42.96^{\circ} \mathrm{N}, 26.89^{\circ} \mathrm{E}$. Location of HiRISE image ESP_036567_2235_RED shown as a dashed line with locations of subsets of the HiRISE image in panels b-e shown as black boxes. (b) LDA stippled texture and competent patch of high-standing mantle material. (c) Contact between LDA and plains, showing the difference in boulder abundance between the two units. (d) Representative example of plains material with many boulders present. (e) A crater in the plains with a remnant patch of mantle that resembles mantle found on the LDA (panel b). 


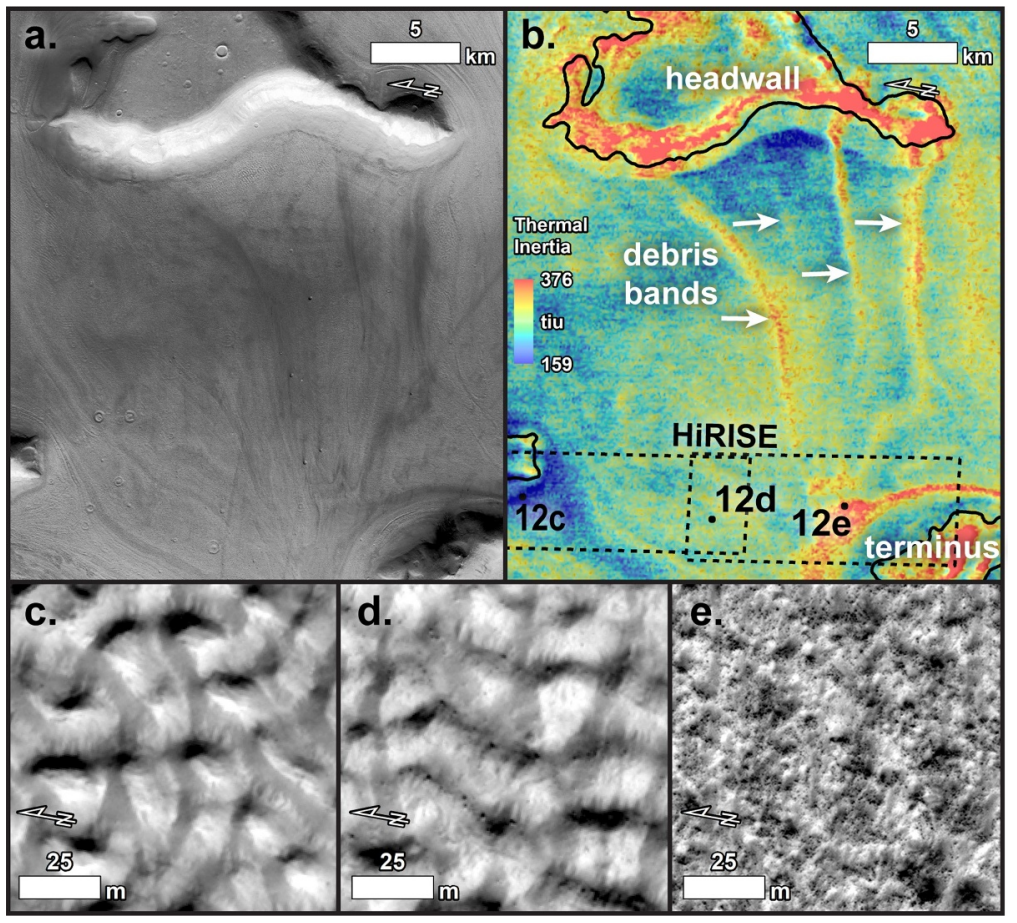

Fig. 12. Low albedo, boulder-rich bands on an LDA, resembling medial moraines. Images in panels a and b are centered at $39.77^{\circ} \mathrm{N}$, $24.50^{\circ} \mathrm{E}$. (a) CTX image mosaic of an LDA showing low albedo bands extending from the headwall (top) to the terminus (bottom). (b) Quantitative THEMIS thermal inertia map (Edwards et al., 2011) of the debris bands and surrounding LDA surface. Locations of HiRISE images ESP_037622_2200_RED and ESP_019359_2200_RED are shown as dashed lines and locations of subsets of the HiRISE images in panels c,d, and e are shown as black dots. (c) Region of low thermal inertia showing top mantle ridges/stippled texture and an absence of boulders. (d) Intermediate thermal inertia showing a mix of boulders and mantle material. (e) Boulder-rich region of high thermal inertia on a debris band near the terminus of the LDA.

crater diameter (and hence depth of excavation) is observed. We observe that $69 \%$ of the craters $(n=70)$ have very little evidence of boulders (boulder conentration values of 0 or 1; see Section 2.6); an additional $29 \%(n=29)$ have only a low to moderate amount of boulders (values 2 to 3 ). The remaining $2 \%$ show abundant evidence for boulders (values 4 to $5 ; n=3$ ). Those craters with abundant boulders are found to have impacted the termini of LDA or were near the sidewalls of thin LVF where more consolidated or greater concentrations of large rocks are present near the surface. In contrast, craters with no boulders are typically formed within mantle material. For example, the $225 \mathrm{~m}$ crater shown in Fig. $6 \mathrm{~b}$ exhibits few boulders in its walls and was formed in a patch of mantle that has been etched into typical LDA, LVF, and CCF stippled texture (Fig. 14a). Where intact, the mantle patches are raised above the surrounding terrain and exhibit fine- scale layering (Fig. 14b). The lack of boulders in the crater is consistent with mantle material or ice making up the majority of the excavated material and for these materials to extend to substantial depth below the surface, potentially up to $45 \mathrm{~m}$ based on the crater's estimated depth (Section 3.4).

Only $6 \%$ of the craters show evidence of layering, with $20 \%$ having possible evidence of layers, observed as discontinuous, topographically prominent ridges paralleling topographic contours of the crater walls. These ridges could not be easily distinguished from stepped slump blocks or other wall-slope features that have been subsequently modified by erosion. One crater shows no boulders in HiRISE and $>10$ continuous, finely spaced layers from near the rim-crest to the floor (Fig. 6a). The diameter of the crater $(166 \mathrm{~m})$ suggests a depth of near $33 \mathrm{~m}$ (Section 3.4), and implies that the layered unit also extends this deep. Further, $8 \%$ of the craters show polygons on their walls, the vast majority ( $82 \%$ ) of which contain little to no visible boulders (values 0 or 1). The polygons are mainly flat-topped, resembling those associated with latitude dependent mantle found throughout the mid-latitudes (Levy et al., 2009a, 2010).

\subsection{Crater depths}

Our measurements of the depths of well-preserved craters on LDA, LVF, and CCF are consistent with the trends of other well-preserved craters on Mars. A detailed global study of well-preserved craters
$25 \mathrm{~m} \leq D_{\mathrm{r}} \leq 5 \mathrm{~km}$ using HiRISE DEMs (Watters et al., 2015) revealed an average $d / D_{\mathrm{r}}$ ratio of $0.18 \pm 0.04$ for the least modified craters and an average of $0.16 \pm 0.04$ for "somewhat modified" craters, including those without crater ejecta and minimal interior fill. Our shadow measurements yield a similar average $d / D_{\mathrm{r}}$ of $0.19 \pm 0.05$ and a power law fit to the data of $d=0.16 D_{\mathrm{r}}^{1.03}$ (Fig. 15a).

In contrast, our measurements from CTX DEMs yield much shallower depths and a low average $d / D_{\mathrm{r}}$ ratio $(0.09 \pm 0.04)$ that we suggest are inaccurate and result from several inadequacies in the data. First, there are likely insufficient DEM pixels to resolve the interior details of most of the craters we measured. Using too few pixels can result in smoothing of the floor and wall topography, producing artificially shallow floor elevations. Over half of the craters were $<20 \mathrm{DEM}$ pixels across, which has been empirically shown to be below the resolution limit for useful morphometric measurements (e.g., MouginisMark et al., 2017). In support, we found that the percent difference between our shadow length measurements and CTX DEM measurements generally decreased with increasing diameter (and hence, number of pixels) (Fig. 15b). There are also interior shadows from the walls of many of the craters. While ideal for shadow-length measurements, these shadows prevented accurate stereo matching in these regions and produced minor artifacts in some of the DEMs that could have affected the depth measurements. A recent evaluation of the utility of CTX DTMs for crater measurements (Mouginis-Mark et al., 2017) demonstrated that crater measurements from CTX DTMs are difficult for $D_{\mathrm{r}}<3 \mathrm{~km}$ due to the limited albedo variations at these scales and bright sunward-facing inner wall slopes that are saturated and make stereomatching difficult. We therefore suggest that the shadow length measurements provide a more accurate representation of depths for our crater size range and discard the CTX DEM measurements from further analysis. We caution that researchers using stereo-derived DEMs in their work should consider the size of features they wish to resolve and ensure that a sufficient number of pixels are present before proceeding with any quantitative measurements.

A $\sim 0.2 d / D_{\mathrm{r}}$ ratio for well-preserved craters on glacial deposits is consistent with their observed morphological "freshness" and suggests that little modification of their shape has taken place since their formation. As craters $>500 \mathrm{~m}$ in size are common, a depth ratio of 0.2 also implies that many craters have penetrated a maximum of $100 \mathrm{~m}$ or 

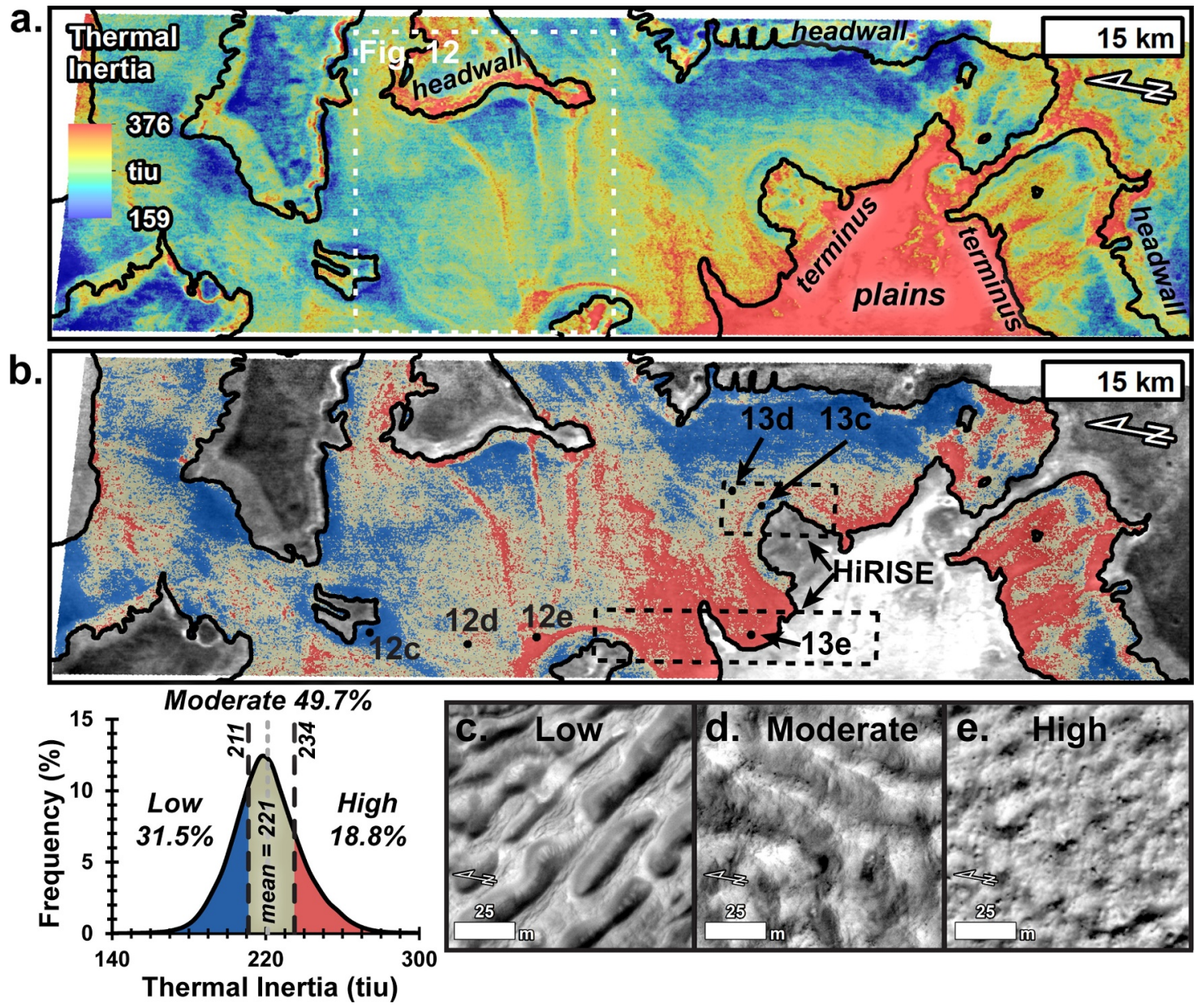

Fig. 13. THEMIS-derived thermal inertia and classified thermal inertia maps of LDA, plateaus, headwalls, and plains, expanded from the region in Fig. 12. (a) THEMIS-derived thermal inertia (Edwards et al., 2011). White dashed outline gives the location of Fig. 12. Solid black lines give the outlines of LDA. (b) Classified thermal inertia units on LDA, as determined from the histogram of LDA thermal inertia values (plot at bottom left) and using the Jenks natural breaks method. Low values ( $<211$ tiu) cover $31.5 \%$ of LDA, moderate values (211-234 tiu) cover 49.7\%, and high values ( $>234$ tiu) cover $18.8 \%$. Black dashed lines give the locations of HiRISE images ESP_032875_2195_RED and ESP_025451_2200_RED. Black dots give the locations of HiRISE image subsets shown in panels c-e. Basemap is a THEMIS nighttime image mosaic. (c) Mantle ridges and no boulders in a low thermal inertia area. (d) Mixture of mantle material and boulders in a region of moderate thermal inertia. (e) Abundant boulders and low-relief mantle in a region of high thermal inertia.

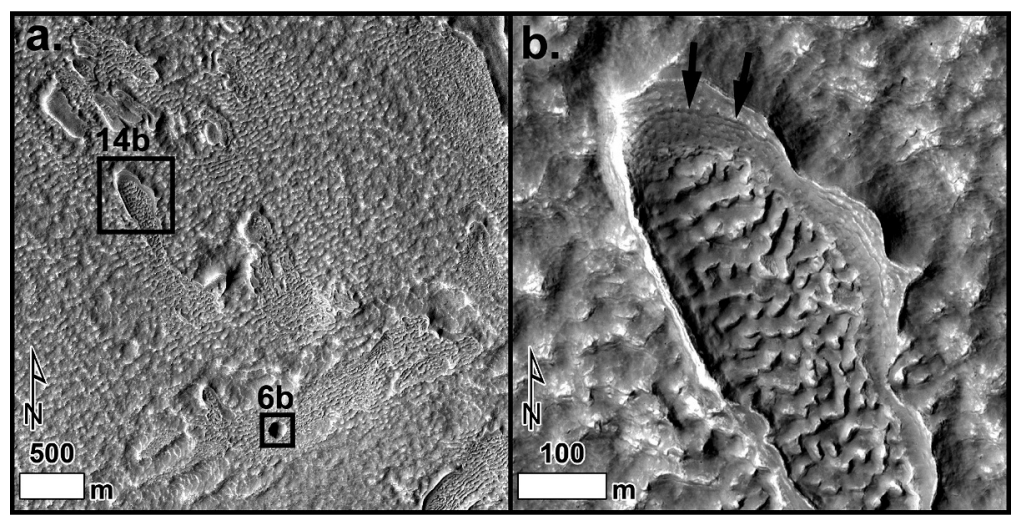

Fig. 14. (a) Example of high-standing mantle patches on an LDA surface. A well-preserved crater (Fig. $6 \mathrm{~b}$ ) has formed in one of the patches. Located near $43.74^{\circ} \mathrm{N}, 24.91^{\circ} \mathrm{E}$. HiRISE image PSP_009733_2240_RED. Inset boxes show the locations of panel $b$ and Fig. 6b. (b) Close-up a mantle patch showing fine layering in its walls (arrows) and degradation to "brain-terrain" textures.

more into the glacial deposits. While the depth of excavation was probably shallower (Section 3.5), these craters potentially excavated substantial amounts of glacial ice and deeper debris layers. This supports the inference that these craters provide important probes into the subsurface and provide important clues to the near-surface properties within their exposed walls (Section 3.3). In the next section we compare the crater depths to the thickness of the glacial deposit determined from SHARAD radar data to confirm the presence of ice and to further demonstrate that the craters formed deep into the glacial ice.

\subsection{Crater depth versus LDA, LVF, and CCF thickness}

We compared the thickness of the LDA and LVF determined from SHARAD radargrams to the depths of excavation $\left(d_{\mathrm{e}}\right)$ and final depths (d) of the corresponding crater (Fig. 16). The depth of excavation was estimated using the relationship of $d_{\mathrm{e}}=0.1 D_{\mathrm{tc}}$, where $D_{\mathrm{tc}}$ is the 
a.

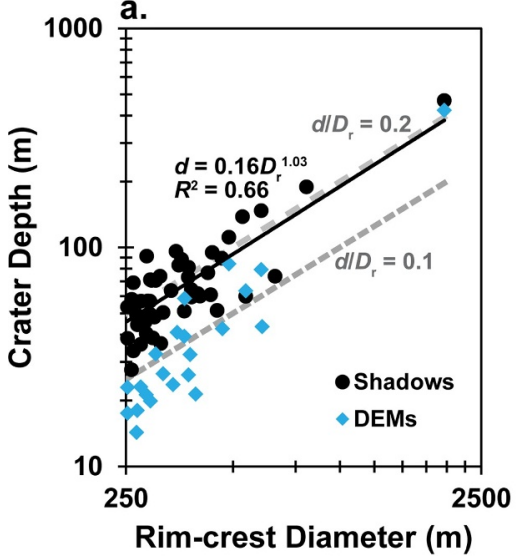

b.

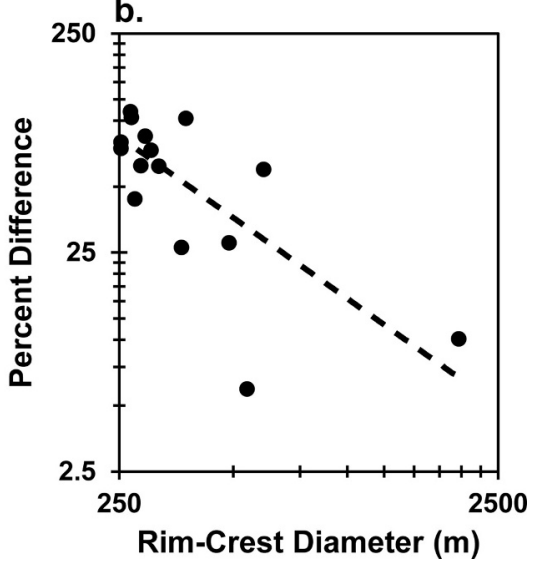

Fig. 15. Crater depth measurements. (a) Crater depth versus rimcrest diameter. Measurements from shadow-lengths (black circles) and CTX DEMs (blue diamonds) are shown, including a power law fit to the shadow-length data (solid black line). Also show are linear trends for depth/diameter ratios of 0.1 and 0.2 for comparison (gray dashed lines). (b) Percent difference between shadow length and CTX DEM measurements of depths for 17 craters. The difference increases with decreasing diameter, due to limitations in the DEM at small crater sizes. (For interpretation of the references to color in this figure legend, the reader is referred to the web version of this article.) a.

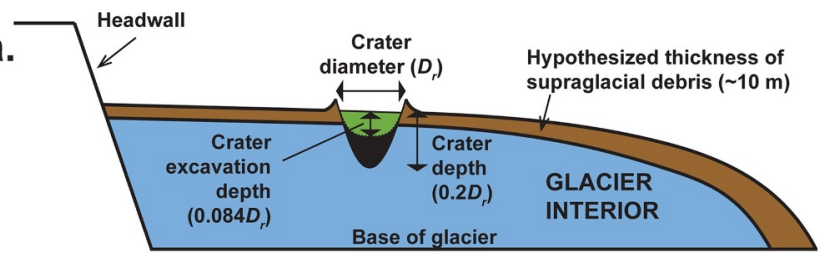

b.

Distance from Headwall $(\mathrm{km})$ $\hat{0}$ ํ

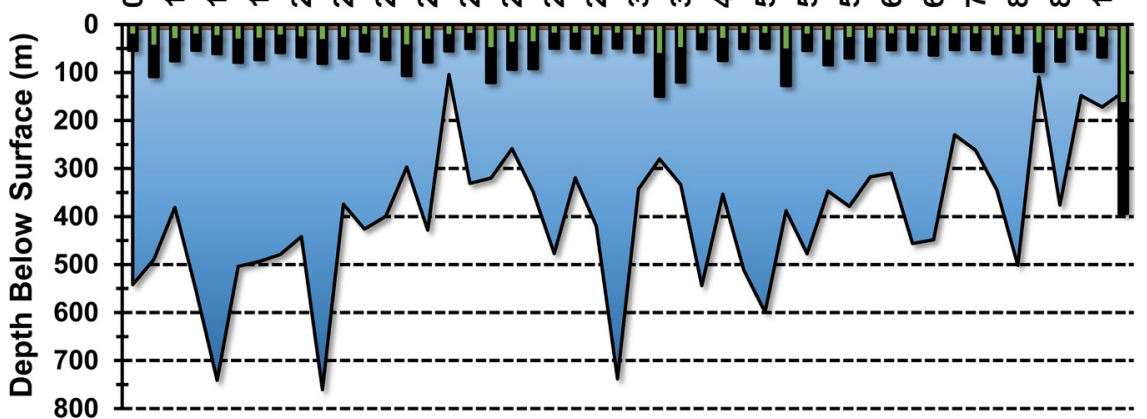

Fig. 16. Thickness of the LDA and LVF glacial ice compared to the depth of craters at the same location. (a) Schematic profile of an LDA showing the parameters plotted in panel (b). (b) Plot of the depth of excavation (green bars) and rim to floor depths (black bars) of craters and the depth to the base of the LDA/LVF at the same location (bottom line). Craters are arranged with increasing distance from the headwall from left to the right. A hypothetical $10 \mathrm{~m}$ debris layer is plotted as a thin brown bar for reference. All of the craters penetrate well beyond this layer and potentially into glacial ice or possibly through it in some cases. (For interpretation of the references to color in this figure legend, the reader is referred to the web version of this article.) transient cavity diameter and $D_{\mathrm{tc}}=0.84 D_{\mathrm{r}}$ (Grieve and Garvin, 1984; Melosh, 1989). The transient cavity diameter is smaller than the final diameter of simple craters by a factor of approximately 0.84 due to slumping of material during modification of the crater interior and due to the fact that transient cavity diameters are measured at the pre-impact surface (whereas, final crater diameter is measured at the rim crest) (Appendix B). For this comparison, we approximate the depths of the craters using $d=0.2 D_{\mathrm{r}}$ based on our morphometric measurements in Section 3.4.

The measured craters are found at a range of distances from their headwall regions (defined as up-gradient wall slopes $>5^{\circ}$ ) and formed into deposits with a range of thicknesses (Fig. 16b). Craters are $4.2 \mathrm{~km}$ from the headwall on average, and are formed into LDA, LVF, and CCF with an average thickness of $396 \mathrm{~m}$. Craters have estimated final and excavation depths of $78 \mathrm{~m}$ and $33 \mathrm{~m}$ on average, suggesting deep penetration of these craters into the glacial ice. Seven of the measured craters have depths of $>100 \mathrm{~m}$, or $>1 / 3$ the thickness of the LDA or LVF. Despite forming deep within the glacier, all of these craters have simple bowl-shaped morphologies that are not obviously modified by the presence of ice or strength contrasts between near-surface layers. This suggests that the inferred icy target in these locations either does not have a substantial effect on morphology during crater formation or shortly post-impact (i.e., within the first $10 \mathrm{Ma}$; Section 3.6) or that the debris layer is many tens of meters in thickness. We evaluate the possibility of a thick debris layer in Section 4.2, below.

\subsection{Crater survival timescale}

We find a best-fit survival timescale of $10 \mathrm{Ma}$ for well-preserved craters $>250 \mathrm{~m}$ (Fig. 17). Craters smaller than $250 \mathrm{~m}$ show a slight rolloff in their frequency that suggests more efficient removal of craters at these sizes (Fig. 17); the survival timescale of these small craters is therefore inferred to be $<10$ Ma. More modified craters necessarily show longer survival timescales when combined with the well-preserved crater data, with all crater types yielding a best-fit crater retention age of $460 \mathrm{Ma}$ (Baker and Carter, 2019).

\section{Discussion}

\subsection{Sources of supraglacial debris}

\subsubsection{Headwall-derived rockfall}

The spatial pattern and boulder-rich characteristics of debris bands found on LDA (Figs. 12 and 13) are reminiscent of terrestrial glacial medial moraines, which can often be traced back to their source region. One of the main formation mechanisms of medial moraines on Earth is through glacial transport of rockfall from the headwall regions or rock spurs downslope toward the glacier terminus (Benn and Evans, 1998 p. 224-227). At the terminus, emergence of englacial sediment and ablation of ice causes a concentration and thickening of sediment in this region. The result is a visible, downslope trail of rockfall that provides a record of its transport pathway from headwall to terminus. 


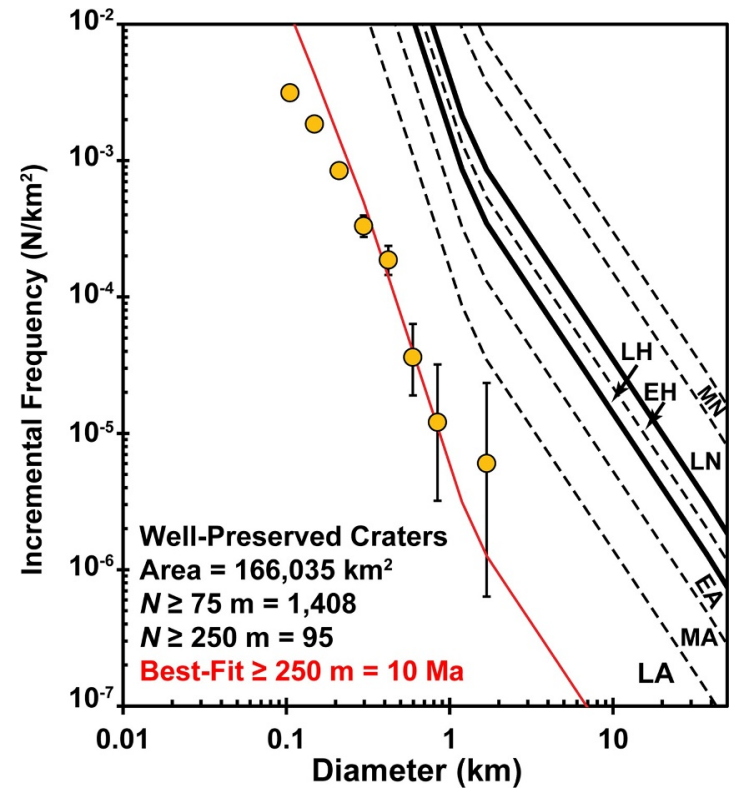

Fig. 17. Incremental crater size frequency distribution for well-preserved craters $\geq 75 \mathrm{~m}$ in diameter on DCGs using Hartmann (2005) isochrons. A best-fit crater retention age is determined at $10 \mathrm{Ma}$ using only craters $\geq 250 \mathrm{~m}$ in diameter. $\mathrm{E}=$ Early, $\mathrm{M}=$ Middle, $\mathrm{L}=$ Late, $\mathrm{N}=$ Noachian, $\mathrm{H}=$ Hesperian, $\mathrm{A}=$ Amazonian.

The presence of similar moraine-like debris bands and abundance of boulders across portions of LDA surfaces, including their termini (Figs. 12 and 13), strongly supports a rockfall origin for a large fraction of the debris covering glacial ice on Mars. The presence of flow lineations extending from alcoves to the termini of LDA and LVF has long been cited as evidence of a rockfall origin of supraglacial debris (Head et al., 2010; Fastook et al., 2014; Levy et al., 2016). However, with our combined evidence from thermal inertia data and boulder abundance, we can now confirm the importance of such sources of debris. As on Earth, this rockfall was sourced from the steep slopes near the accumulation zones and valley walls of the glacial deposits and then transported downslope via glacial flow. The rockfall can be transported supraglacially or englacially, although it is generally transported englacially when it is buried by ice and snow in the accumulation zone (Mackay et al., 2014).

On Earth, supraglacial debris can thicken with time across the glacier surface due to ablation of glacial ice and liberation of englacial debris. For example, around $70 \%$ of the supraglacial debris on the analog Mullins Valley debris-covered glacier in the Antarctic Dry Valleys is estimated to be derived as a sublimation lag of englacial debris (Marchant et al., 2002; Mackay et al., 2014). At the Mullins Valley glacier, near-surface debris content in glacial ice is generally small at $\leqslant 1 \%$ by volume with higher concentrations of $35 \%$ found in association with narrow englacial debris bands (Mackay et al., 2014). The internal debris content of LDA and LVF glacial ice is constrained to be $<10 \%$ based on radar observations (Holt et al., 2008); therefore sublimation of glacial ice would likely produce a comparatively thick or thicker sublimation lag that would thicken with time. It is therefore possible that the present boulder-rich surfaces of LDA, LVF, and CCF may be the manifestation of thick sublimation lags or tills (Head et al., 2010). Evidence of glacial highstands suggests that LDA and LVF have lowered in elevation by as much as several hundreds of meters as accumulation ceased and ablation dominated (e.g., Dickson et al., 2008). Even for a modest $10 \mathrm{~m}$ of lowering of ice with $10 \%$ debris content, a $\sim 1 \mathrm{~m}$ thick sublimation lag would be produced.

The properties of the debris, including clast size and composition should be affected by the rock types and erosional history at the headwalls. Terrestrial medial moraines and supraglacial debris covers often consist of a range of clast sizes, from sand-sized grains to boulders (Benn and Evans, 1998; Marchant et al., 2002; Levy et al., 2006). Englacial debris could also contain both transported rockfall and dust that was deposited concurrently with snow and ice that formed the glaciers. Thus, any sublimation lag contributing to the thickness of the supraglacial debris layer is likely to be poorly sorted and may consist of clasts ranging from dust to boulders. The concentration of boulders within the debris bands on martian LDA is consistent with terrestrial examples, although boulders are likely not the dominant clast size. HiRISE images cannot resolve features smaller than about $1 \mathrm{~m}$; thus, insitu or higher resolution remote sensing measurements are needed to confirm the actual size distribution.

Furthermore, our observations suggest that away from the debris bands and regions of high boulder abundance, the rockfall is covered by finer-grained mantle (Section 4.1.2), explaining the lack of exposed boulders and lower thermal inertia at these locations. The current exposures of boulders within the debris bands could be explained by a higher concentration of rocks of all sizes at these locations, a characteristic of moraines (Benn and Evans, 1998), and thinner mantle at these locations, which could possibly be related to the relative higher topography of the debris bands compared with the surrounding terrain.

\subsubsection{Atmospherically deposited mantle}

We infer based on our observations that finer-grained mantle superposes the headwall sediment and forms layered patches and textures over much of the LDA, LVF, and CCF surface (Figs. 5e, 11b, 12c, 13c, 14). This is consistent with previous work suggesting the substantial role that atmospherically deposited ice and dust mantles have had in modifying the surfaces of LDA, LVF, and CCF (Mangold, 2003; Pierce and Crown, 2003; Levy et al., 2009b; Berman et al., 2015; Baker and Head, 2015). We find that the walls of well-preserved craters typically do not show significant fractions of clast sizes greater than $\sim 1 \mathrm{~m}$ (limit of HiRISE). This suggests that the clast size of supraglacial debris for most of its depth is $<1 \mathrm{~m}$. and that much of its thickness may be airfallderived. Further only $3 \%$ of the craters preserve their ejecta, which is consistent with highly mobile fine-grained and/or icy materials. This ejecta is derived from $>100 \mathrm{~m}$ depth is some cases (Fig. 16), also indicating that the fine-grained and/or icy character extends well into the subsurface or that a substantial portion of the ejecta is glacial ice.

While the transport and accumulation of headwall sediment across the glacial surface ceased with the inferred cessation of glacial flow around $500 \mathrm{Ma}$ to $1 \mathrm{Ga}$, mantle emplacement has occurred repeatedly throughout the Middle to Late Amazonian to as recently as $\sim 0.1 \mathrm{Ma}$ (Kostama et al., 2006; Schon et al., 2009). The most recent episode is observed as latitude dependent mantle (LDM) across the mid-latitudes of Mars, which was also deposited on LDA, LVF, and CCF (Levy et al., 2009b). Surveys of HiRISE images record up to six layers, each meters in thickness, within the LDM (Schon et al., 2009). Head et al. (2003) predict that the LDM was formed as interlayered ice and dust-rich sequences that record the most recent oscillations in the planet's obliquity. Impact events into LDM and occurring within the last decade have exposed pure ice from depth within the LDM (Dundas et al., 2014). In addition, HiRISE images and reflectance and thermal infrared data have revealed exposed ice in $\sim 100 \mathrm{~m}$ high walls of LDM (Dundas et al., 2018), confirming these predictions. Evidence of older airfall deposits up to $100-\mathrm{m}$ thick and at least $\sim 500$ Ma old is preserved within the plains of Deuteronilus Mensae (Baker and Head, 2015). Similar airfall units occur as Middle Amazonian loess-like deposits throughout the Northern Lowlands (Skinner et al., 2012), and as highstanding remnants associated with pedestal craters, having a median age of 140 Ma (Kadish et al., 2009; Kadish and Head, 2014). The superposition of distinct classes of depressions within icy mantle within the Argyre region also suggests multiple episodes of mantle deposition and modification (Soare et al., 2017). The preservation of these older units indicates that deposition of thick packages of icy dust occurred throughout the Amazonian, adding substantial thicknesses of material 
to the tops of LDA, LVF, and CCF, as documented here.

\subsection{Thickness of supraglacial debris}

The rockfall and airfall sources of debris, combined with the ancient ages of debris-covered glaciers on Mars (Fassett et al., 2014), makes the characteristics of supraglacial debris unique compared to debris-covered glaciers on Earth. Where supraglacial debris on Earth is typically $<2 \mathrm{~m}$ in thickness (e.g., Benn and Evans, 1998; Marchant et al., 2002; Levy et al., 2006), on Mars, the downwasting of ice and the repeated deposition of mantle over the past hundreds of millions of years have led to enhanced debris thicknesses with a much different stratigraphy. We discuss the evidence for the thickness of martian supraglacial debris, below.

\subsubsection{Topographic constraints and debris heterogeneity}

A minimum thickness estimate for the supraglacial debris comes from the thickness of surface mantle deposits. HiRISE DEMs show topographic roughness, mainly within mantle, on the scale of at least 1-5 m, with some mantle patches at least $\sim 10-20 \mathrm{~m}$ in height (Petersen et al., 2016, 2017; Baker, 2018). We therefore suggest that, at a minimum, the debris cover is a few meters in thickness were mantle is present. Baker and Head (2015) report mantle thicknesses of 50-100 m for deposits preserved in the plains surrounding LDA (i.e., "Upper Plains", Fig. 3). These deposits were more widespread in the past and evidence suggests that they drape LDA in the region. Although erosion and sublimation of contained ice has occurred, it is possible that thick sequences of mantle are still preserved in some portions of the study area, contributing to tens of meters of material at these locations.

We suggest that the northern portions of the study area contain relatively thicker mantle cover due to textures that are least developed (Sections 2.2 and 3.1, Fig. 5e) and possibly linked to greater preservation of continuous patches of mantle at these locations (Fig. 3, Section 2.1). The southern portions of the study area exhibit more developed textures and higher thermal inertia (Figs. 4 and 8b). Some of these regions are also associated with debris-bands and boulder-rich areas (Figs. 12 and 13) that we interpret as rockfall debris exposed at the surface. Therefore, mantle is interpreted to be thinner at these locations and the entire supraglacial debris package may be thinner. In the sub-region of LDA investigated here (Fig. 13), which is located in the southern portion of the study area, we estimate that as much as $\sim 20 \%$ of the surface has high boulder abundance and only possesses a relatively thin $(<1 \mathrm{~m})$ layer of mantle as to not obscure the visible boulders. In the same sub-region, thicker mantle occurs over the remaining $\sim 80 \%$ of the surface, with $\sim 30 \%$ of the surface estimated to have few to no boulders due to the presence of mantle at least a few meters in thickness. Further, the presence of regions with high boulder abundance at LDA termini (Fig. 13) suggests that glacially transported debris also becomes more concentrated and possibly thickens toward the LDA termini, as occurs in glacial systems on Earth. Due to the inferred thinner mantle in the equatorward portions of the study region, we predict that the thinnest debris cover may be located in the most equatorward locations near the headwalls of LDA and LVF. However, the depth to stability for ice increases toward the equator (Mellon and Jakosky, 1995), which would imply greater sublimation of ice and equatorward thickening of the debris cover through development of a thicker sublimation lag. Therefore it is possible that thinning of the entire supraglacial debris package due to the absence of mantle may be offset by a thickening of the debris due to greater depth to ice at the same locations. Our present observations cannot distinguish between these scenarios.

\subsubsection{Crater terracing}

Assuming minimal erosion, the lack of terracing or other interior structures within well-preserved craters over a range of sizes implies that no substantial strength differences occur within the top tens of meters of the surface (Senft and Stewart, 2007, 2008). Either the debris layer is thick over the crater depth range, the internal layering (i.e., between mantle and headwall-derived sediment) and glacial ice share similar strengths, and/or there is a gradational contact between the surface of the debris and start of pure glacial ice. Terraces occur in craters $<1 \mathrm{~km}$ in size within Arcadia Planitia that are interpreted to have resulted from strength contrasts between ice-poor regolith and subsurface ice sheets on the order of $10 \mathrm{~m}$ in thickness (Bramson et al., 2015). By analogy, similar modification of recently formed craters on LDA, LVF, and CCF would appear likely, however, they are not observed.

We therefore prefer either a thick debris package or an absence of large strength contrasts between the debris and glacial ice (or both) for the structure of supraglacial debris. The presence of fine layers suggestive of mantle material and spanning the entire $\sim 30 \mathrm{~m}$ depth of one crater (Fig. 6a) suggests that thick supraglacial debris is present in at least some locations. The unconfined compressive strength of ice is on order of $10 \mathrm{~s}$ of MPa (Haynes, 1978), while cohesive soils typically have strengths of $<1 \mathrm{MPa}$, with unconsolidated soils or regolith having zero to little compressive strength (Gertsch et al., 2008). While the exact strength contrasts required to produce terracing in craters are not well constrained, Quaide and Oberbeck (1968) produced terracing in their laboratory impact experiments with target strength contrasts of $140 \mathrm{kPa}$ and $6.85 \mathrm{MPa}$. Therefore, the observed absence of terracing between layers appears to require a reduction in the strength contrast with ice through significant strengthening of the supraglacial debris layer (Senft and Stewart, 2007). Cementation of the debris by pore ice is one possible strengthening mechanism (Gertsch et al., 2008), and would imply a gradational contact between the debris and underlying glacial ice. The absence of near-surface reflectors in SHARAD radargrams (Section 4.3.1) is consistent with a gradational contact and hence absence of a dielectric contrast.

A gradational contact between supraglacial debris and glacial ice is at odds with the sharp contacts observed for debris-covered glaciers on Earth, such as Mullins Valley glacier (Marchant et al., 2002; Marchant and Head, 2007; Mackay et al., 2014). If correct, a gradual increase in ice content across the debris-ice interface for LDA, LVF, and CCF requires a mechanism to generate pore ice. It is possible that the deposition of ice-containing mantle on top of LDA, LVF, and CCF raised the ice table within the debris or reversed the water vapor gradient such that water was driven into subsurface pore space. Another possibility is that LDA, LVF, and CCF were warmer in the past, which lowered the ice stability depth and drove sublimation toward depths deeper than the current ice table. Subsequent cooling of the LDA, LVF, and CCF and rising of the ice table to its present depth would have allowed any water vapor to migrate through the debris and fill the available pore space up to the ice table. This could imply higher surface temperatures in the past, possibly related to periods of low obliquity, where temperatures in the mid-latitudes were higher than present (Bramson et al., 2017). Future models and measurements should attempt to better test the hypothesis of a gradational contact and the mechanisms for producing it. For example, confirming the presence or absence of ice within mantle with orbital data or future landed missions and modeling of water vapor migration through the supraglacial debris under different stratigraphies and climate scenarios would help to determine if the mechanisms offered above are plausible. Future radar sounding instruments at frequencies of a few hundred $\mathrm{MHz}$ and vertical resolutions of $<1 \mathrm{~m}$ could help to further constraint how ice and debris content vary with depth. Although likely cost prohibitive, a more direct way to assess ice content with depth would be to drill or excavate through meters of the debris with future landed missions.

\subsubsection{Ice exposed in crater walls}

The estimated 10 Ma survival timescale for well-preserved craters (Fig. 17; Section 3.6) suggests that, as a population, they have experienced large changes in insolation and climate conditions since their 
formation. In particular, the craters would have been subjected to insolation and ice and dust depositional changes associated with large swings in Mars' obliquity, including $\sim 100 \mathrm{kyr}$ cycles with swings of $20^{\circ}$ (Head et al., 2003; Laskar et al., 2004). Further, at 5 Ma, the mean obliquity changed from a mean value favorable to ice deposition in the mid-latitudes near $35^{\circ}$ (Madeleine et al., 2009, 2014) to a mean value more favorable to sublimation near $25^{\circ}$. Many excursions above $30^{\circ}$ obliquity over timescales of 20-40 kyr occurred in the past $5 \mathrm{Ma}$, leading to deposition of centimeters-thick ice layers that remained stable under dusty sublimation lags upon return to lower obliquity (Mustard et al., 2001; Head et al., 2003). Despite these swings in obliquity and episodes of mantle deposition, the morphology and depthto-diameter ratios (Section 3.4) of well-preserved craters on LDA, LVF, and CCF suggest little modification of shape through this time period. This is also perplexing given the icy nature of the substrate they impacted into (Section 3.5). Recent modeling work (Dundas et al., 2015; Dundas, 2017) shows that crater-like depressions within icy regolith exhibit observable rounding and widening of the rim and shallowing of the crater floor within a few million years. Observations of expanded secondary craters in other parts of the mid-latitudes (Viola et al., 2015) also suggests that icy near-surface layers act rapidly to modify small crater shapes. Based on these results, we expect that craters formed within nearly pure glacial ice, as is the case for most of the craters studied, would undergo even more rapid modification.

To help explain this apparent contradiction in observations, we investigated the role that supraglacial debris layer thickness and debris slumping have in reducing the amount of ice exposed in craters during their formation. The debris layer will act to limit ice exposed to sublimation by forming the upper fraction of the crater wall and contributing to material that is slumped into the crater center (Fig. 18). If not further inhibited, later post-impact sublimation of the exposed ice (which is not included in the model) would act to modify this initial crater shape through undermining of the overlying debris layer. We modeled the surface area of ice exposed by a crater using an analytical geometric model developed from observations of terrestrial simple impact craters (Grieve and Garvin, 1984). The model approximates the shape of the transient cavity and final crater by paraboloids, with slumped material estimated by the volumetric difference between the

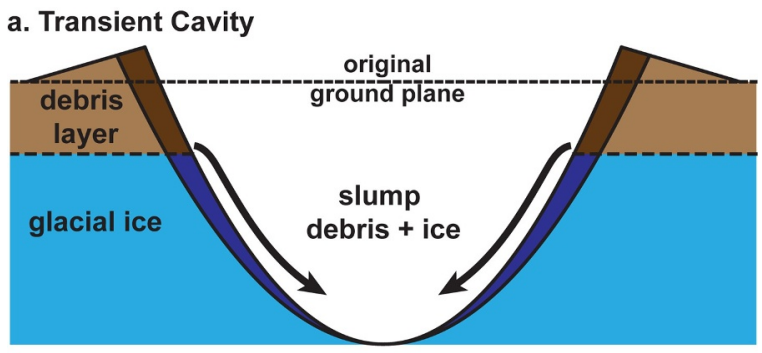

\section{b. Final Cavity}

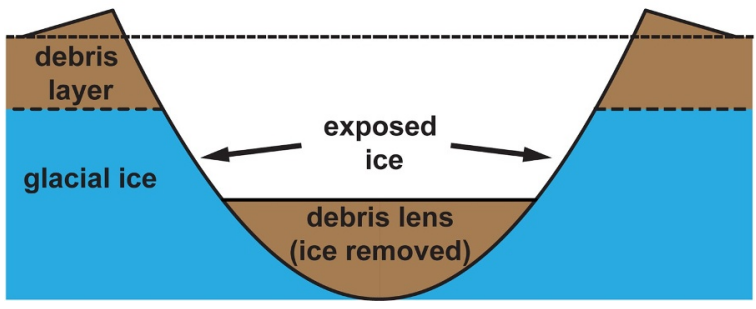

Fig. 18. Sketch of crater debris slumping scenarios, as modeled and described in Appendix C and Section 4.2.3. (a) Pre-slumping. The difference in transient cavity and final cavity paraboloids (shaded areas) is assumed to contribute to a final debris lens in the center of the cavity after slumping (panel b). Ice is predicted to be exposed between the base of the supraglacial debris layer and top of the debris lens. two cavities (Appendix C). We assume that the slump material forms a lens at the center of the crater, as most of the wall slopes are too steep for debris to be stable (Appendix C).

We find that at a debris layer thickness of $\geq 0.52 d_{t}$ (where $d_{t}$ is the transient crater depth), no ice is predicted to be exposed (Fig. 19a) because the lens of slumped debris is thick enough to completely cover the ice in the center of the crater. This depth ratio corresponds to a debris layer thickness of about $10 \mathrm{~m}$ for a $100 \mathrm{~m}$ crater, $26 \mathrm{~m}$ for a $250 \mathrm{~m}$ crater or $78 \mathrm{~m}$ for a $750 \mathrm{~m}$ crater (Fig. 19b). If we assume a uniform debris thickness of $\sim 25 \mathrm{~m}$, a possible upper limit based on radar (Section 4.3, Fig. 21b), craters $\geq 162 \mathrm{~m}$ would have some fraction of ice exposed within their walls. A $250 \mathrm{~m}$ crater would have $\sim 20 \%$ ice exposure and a $500 \mathrm{~km}$ crater would have $\sim 47 \%$ ice exposure. In the absence of additional sources of debris cover, substantial modification of these craters is expected after sublimation of exposed ice; debris thickness would therefore likely need to be greater to be consistent with morphological observations. However, additional debris from sublimation lags and aeolian deposited material could also contribute to inhibit sublimation. One meter of ice loss at the walls of the craters would produce a $10 \mathrm{~cm}$ lag deposit if $10 \%$ debris is present, which may be sufficiently thick to limit further sublimation if the debris remains stable on the steep crater walls (Schorghofer and Forget, 2012; Bramson et al., 2017). Furthermore, the latitude dependent mantle and other aeolian sediment were also deposited during the $10 \mathrm{Ma}$ survival timescale of the craters (Head et al., 2003; Madeleine et al., 2014). Some crater walls exhibit thermal contraction crack polygons (Fig. 6b and e), common characteristics of icy or ice-rich LDM deposits throughout Mars (e.g., Levy et al., 2009a, 2009b, 2010). These polygons may also be related to shallow glacial ice in the walls of the craters (Levy et al., 2006), although their occurrence near the crater rim crest is more consistent with formation within LDM.

Our geometric model also does not consider the "injected" target material that is displaced downward and outward by the excavation flow field (e.g., Croft, 1980). While the top $\sim 1 / 3$ of the crater is ejected out of the crater, the bottom $\sim 2 / 3$ is displaced or "injected" into the target, resulting in a deeper crater and formation of the structural rim uplift. Unexcavated layers will therefore be displaced outward and compressed to line the transient cavity and final crater. In the case of our two-layer stratigraphy, when the excavation depth is near or shallower than the debris layer thickness $\left(d_{\mathrm{e}} \leq t_{\text {debris }}\right.$ ), debris that is not excavated will be displaced to line the bottom and walls of the crater. The thickness of this lining is difficult to estimate without numerical modeling or experiments, however compression during displacement will compact the debris so that its final thickness is much less than its original thickness (Croft, 1980). Depending on the thickness of the lining, slumping may or may not expose ice in the crater walls. We estimate that when $t_{\mathrm{debris}} \geq d_{\mathrm{e}}$ or $t_{\mathrm{debris}} / d_{\mathrm{t}} \geq 0.29$ in our model (assuming $d_{\mathrm{e}}=0.1 D_{\mathrm{tc}}$ ), a sufficiently thick debris lining may be present to protect ice in the crater walls that would otherwise be exposed after slumping. When $t_{\mathrm{debris}}<d_{\mathrm{e}}$, excavation is below the debris layer and the displaced debris and resulting debris lining is minimal or absent. For the case when $t_{\text {debris }}=25 \mathrm{~m}$, craters $<250 \mathrm{~m}$ in diameter will have excavated exclusively into the debris layer and a combination of the exposed debris layer, displaced debris lining, and slumped debris will act to protect any exposed glacial ice in the crater. Craters $>250 \mathrm{~m}$ would have fractions of exposed ice near the values estimated in our simple geometric model (i.e., $f_{\text {ice }}>20 \%$; Fig. 19b)

More complete numerical modeling of impacts into debris-covered ice and post-impact sublimation of near-surface ice along with additional morphometric measurements should be conducted to further evaluate the importance of the myriad of processes acting to modify these craters post-impact.

\subsection{Radar constraints}

\subsubsection{Absence of near-surface reflectors}

From our analysis of 648 SHARAD radargrams (Section 2.8.1), we 
a.

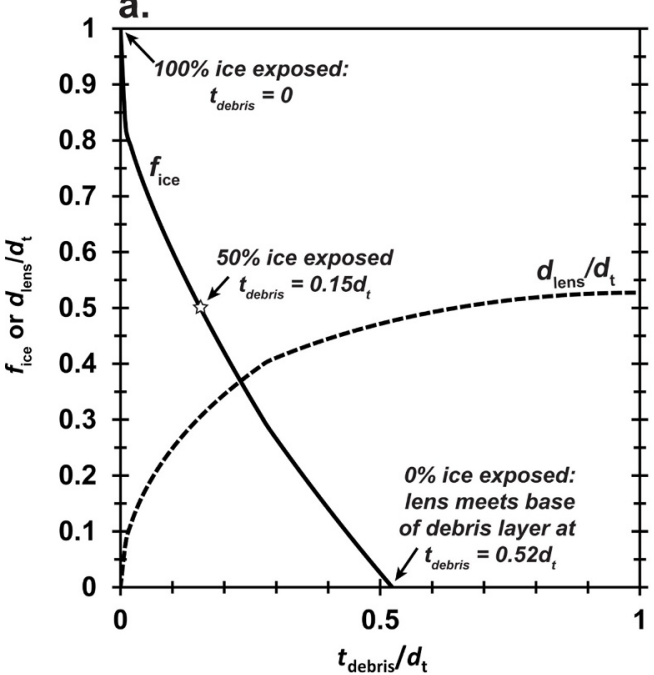

b.

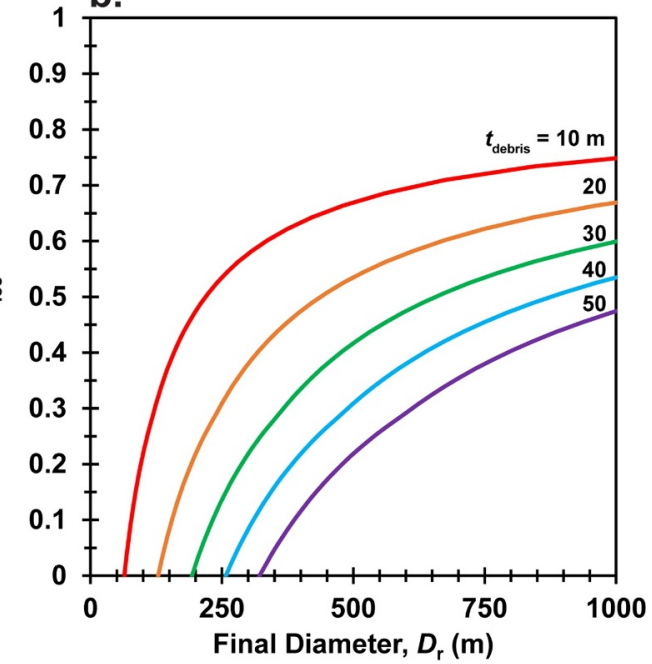

Fig. 19. (a) Areal fraction of ice exposed in crater walls $\left(f_{\text {ice }}\right)$ as a function of thickness of the supraglacial debris layer $\left(t_{\text {debris }}\right)$ normalized to the depth of the transient cavity $\left(d_{t}\right)$. Also plotted are the normalized depths to the top of the debris lens $\left(d_{\text {lens }}\right)$. (b) Areal fraction of ice exposed as a function of final crater diameter for debris layer thicknesses between 10 and $50 \mathrm{~m}$. found no candidate near-surface returns that could be confidently attributed to reflections off a subsurface interface between supraglacial debris and glacial ice. In contrast, returns from the base of the LDA and LVF are prevalent and often appear as high-power returns, with little apparent attenuation (Fig. 7a and Plaut et al., 2009).

The simplest explanation for the lack of near-surface reflectors in SHARAD radar data is a supraglacial debris layer that is thinner than the $\sim 10 \mathrm{~m}$ vertical resolution of SHARAD. However, the above morphologic evidence suggests the presence of a mantle and rockfall component for the debris layer that, together, may be tens of meters in many locations, which should be detectable by SHARAD. To test the potential of supraglacial debris to produce an observable reflection that can be resolved in SHARAD radargrams, we first used a simple twolayer radar transmission model (Appendix D) and predicted travel times (Appendix B) to investigate the expected power and two-way return times of reflections off the base of the debris layer in contact with glacial ice.

Little dielectric contrast is needed to produce a reflection that is greater in relative power than the expected radar sidelobes (Fig. 20a). For example, the interface between a $15-\mathrm{m}$ thick debris layer and glacial ice having a real permittivity $(\varepsilon)$ of 3.15 will produce a radar reflection with a relative magnitude dependent on the debris layer's permittivities and loss properties, commonly evaluated through the loss tangent. The loss tangent, $\tan \delta$, of a material is the ratio of the imaginary to real components of the permittivity and varies with composition and structure of the material (Campbell, 2002). For tan $\delta=0.01$ for the debris layer (fairly high for fine-grained, low density deposits), permittivities of $<2.85$ or $>3.6$ will produce returns above the power of both the first and second sidelobes (Fig. 20a). Smaller loss tangents reduce this range only slightly. With the exception of the highest loss tangents, these results also do not change significantly with increasing thickness of the debris layer. The above model is for a sharp contact between debris and ice. However, a gradational contact between the debris layers and glacial ice is possible, and would not produce a strong radar return, as the change in permittivity would be too gradual to be detected by SHARAD. This may be likely if a lag builds up from below the debris layer as the interfacial ice sublimes through vapor diffusion and deposits its suspended sediments (Section 4.1.3). However, a mechanism to fill pore space with water ice appears to be required (Section 4.2.2).

We also find that much overlap is expected between the time-delays of returns from a debris-ice contact and expected sidelobe pattern (Fig. 20b). We investigated a range of debris layer thicknesses from $15 \mathrm{~m}$ to $50 \mathrm{~m}$ and permittivities between 2 and 5 in our model. Since a single pixel in SHARAD radargrams is $0.0375 \mu$ s, we identified any modeled returns with time-delays of $0.24 \pm 0.04 \mu$ s or $0.42 \pm 0.04 \mu \mathrm{s}$ as coinciding with a sidelobe. Considering that $\varepsilon$ for the debris layer is most likely $\geq 3.5$ due to its rock content (Section 4.1), we find that layer
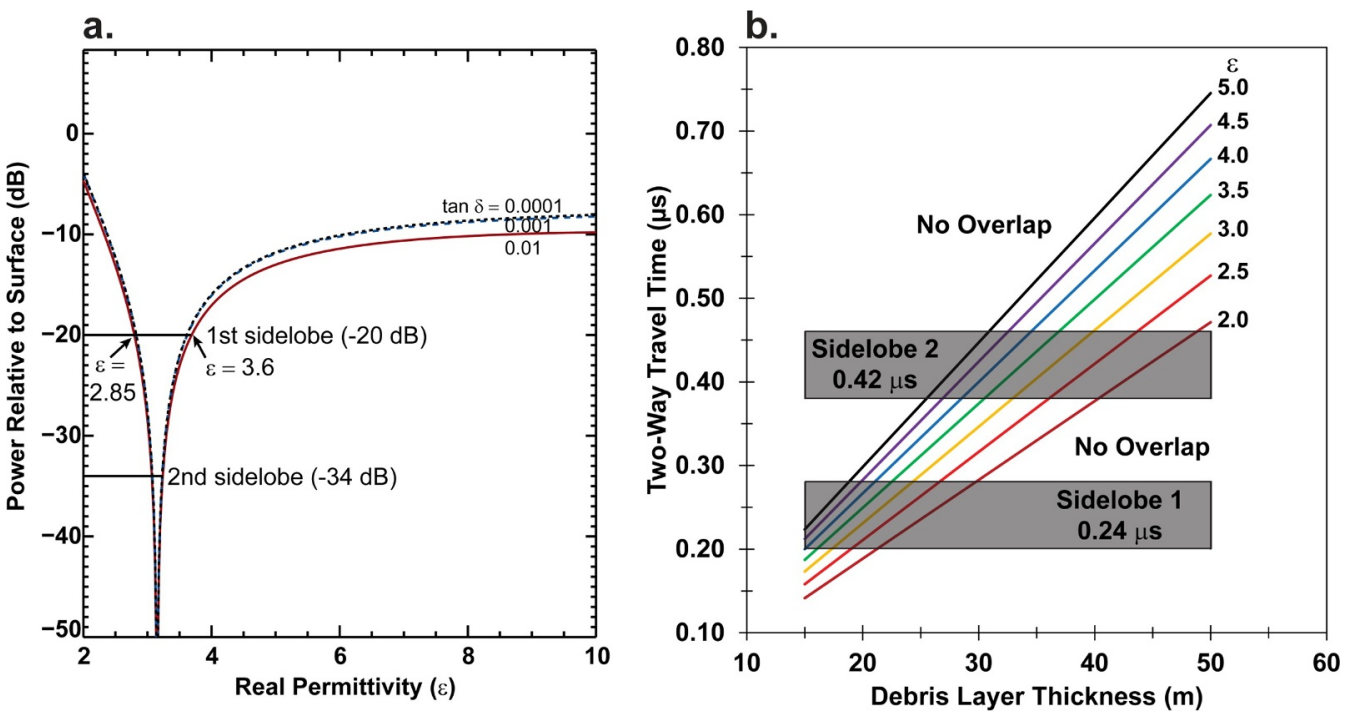

Fig. 20. (a) Modeled radar power reflected off the bottom of a supraglacial debris layer $15 \mathrm{~m}$ in thickness in contact with glacial ice compared with the expected power of the first and second sidelobes (Putzig et al., 2014). Shown are results for a range of debris layer real permittivities $(\varepsilon)$ and loss tangents $(\tan \delta$ ) (see Table D1, Model 1). Glacial ice is assumed to have $\varepsilon=3.15$. (b) Modeled two-way travel time of a reflection off the bottom of debris layer in contact with glacial ice compared with the expected occurrence of the first and second sidelobes (Putzig et al. 2014). Boxes represent the values reported by Putzig et al. (2014) +/one radargram pixel (0.0375 $\mu$ s). Shown are results for a range of debris layer thicknesses and real permittivities. 
thicknesses of near 15-20 m will significantly overlap with the first sidelobe and layers $\sim 30-35 \mathrm{~m}$ will significantly overlap with the second sidelobe (Fig. 20b). Therefore, layers with thickness of between $\sim 20-30 \mathrm{~m}$ and $>40 \mathrm{~m}$ will yield the best opportunity of being resolved by SHARAD.

Based on the above models and regions with debris cover likely $>10 \mathrm{~m}$ (Section 4.2), we suggest that the absence of near-surface reflectors in SHARAD data is likely due to a lack of contrast in permittivity due to a gradational contact between the debris layer and glacial ice. This is also consistent with the lack of terracing within craters and the fine-grained or icy material extending to great depths within the craters. Alternatively, if large contrasts in permittivities did exist, detecting their presence may be hindered by the presence of sidelobes or clutter, which are present in most radargrams and occur at time delays coincident with expected ranges of debris layer thicknesses.

\subsubsection{Radar constraints on debris thickness}

Despite the lack of distinct near-surface reflectors (Section 4.3.1), it is still possible to place constraints on the thickness and dielectric properties of a supraglacial debris layer using the characteristics of the observed LDA and LVF basal returns (Sections 2.8.2 and 3.5). Previous work has estimated a bulk permittivity of 3.15 for LDA, which is that of nearly pure ice with a $<10 \%$ internal rock fraction (Holt et al., 2008; Plaut et al., 2009). This was based on observations of alignment between the base of LDA in depth-corrected radargrams and the adjacent flat-lying plains. Recent measurements of 507 SHARAD radargrams over LDA and LVF (Petersen et al., 2018) show that the real permittivity is $3.2 \pm 1.2$ for all LDA and LVF in Deuteronilus Mensae. The large uncertainty was attributed to uncertainties in estimating the basal topography of the features, which is used to constrain the value of the permittivity. How thick can a supraglacial debris layer be and still be consistent with these assumed bulk values? For a two-layer stratigraphy, such as a debris layer on ice, the bulk permittivity of the layers will be proportional to the thickness of each layer:

$\varepsilon_{b}=\sum\left(\frac{t_{i}}{t_{b}} \sqrt{\varepsilon_{i}}\right)^{2}$

where $\varepsilon_{\mathrm{b}}$ and $\varepsilon_{\mathrm{i}}$ are the bulk and individual layer permittivities and $t_{\mathrm{b}}$ and $t_{\mathrm{i}}$ are the bulk and individual layer thicknesses, respectively.

To be consistent with the estimated value of $\varepsilon_{\mathrm{b}}=3.15$ (Holt et al., 2008; Plaut et al., 2009), a debris layer thickness $\left(t_{1}\right)$ is required to be zero if the permittivity of the debris layer $\left(\varepsilon_{1}\right)$ is different from 3.15 and the permittivity of glacial ice is known for certain to be $\varepsilon_{2}=3.15$ (Fig. 21a). However, as Petersen et al. (2018) show, the average permittivity value for LDA and LVF in Deuteronilus Mensae has a large uncertainty of \pm 1.2 , or nearly $\pm 40 \%$. If a $5 \%$ uncertainty in $\varepsilon_{\mathrm{b}}$ can be constrained for some LDA with well-defined basal topography, a maximum debris thickness of near $80 \mathrm{~m}$ is allowable for $\varepsilon_{1}=4.0$ and near $40 \mathrm{~m}$ for $\varepsilon_{1}=5.0$ (Fig. 21a). A $10 \%$ uncertainty allows for layer thicknesses $>100 \mathrm{~m}$, and a $2.5 \%$ uncertainty allows for a maximum thickness of near $40 \mathrm{~m}$. A debris layer thickness of $<10 \mathrm{~m}$ is most consistent if $\varepsilon_{\mathrm{b}}$ is known to be $\leq 3.2$. Clearly, additional work is needed in order to further reduce the uncertainties in $\varepsilon_{\mathrm{b}}$ across the mid-latitudes of Mars. Without these constraints, a wide range of debris thicknesses is possible when examining bulk permittivity alone.

We can further help to constrain the thickness of the debris layer by examining how attenuation through the debris layer affects the radar signal returned from the base of the LDA and LVF (Fig. 21b). The degree of radar attenuation will be affected by the assumed permittivity, thickness, and loss tangent of the layers (Appendix C). We modeled the reflection and transmission of the radar signal through a simple threelayer stratigraphy of debris, ice, and basement rock (Appendix $\mathrm{C}$ ). We assumed $\varepsilon_{2}=3.15$ and $t_{2}=396-t_{1}$ (in meters) for the ice layer, calculated from the average of our LDA and LVF thickness measurements (Section 3.5) and $\varepsilon_{3}=8.0$ for the basement rock, which is consistent with a volcanic origin of plains material in the region that is assumed to extend beneath the LDA and LVF (Chuang and Crown, 2009). We modeled the returned power of the radar signal reflected off the base of the glacier by varying $\varepsilon$, $t$, and $\tan \delta$ for the debris layer and comparing against an average return value of $-4.5 \mathrm{~dB}$ (relative to the surface reflection; average value from measurements in Sections 2.8.2 and 3.5). We investigated a debris layer with moderate loss properties (tan $\delta=0.001)$ and high loss $(\tan \delta=0.01)$ for $\varepsilon_{1}=4.0,5.0$, and 6.0 (Fig. 21b).

Only two models produce basal returns with enough power to be consistent with observations, constraining $\varepsilon_{1}$ to be near 4.0 and $t_{1}$ to be $\lesssim 25 \mathrm{~m}$ on average (Fig. 21b). Greater permittivities or thicknesses for the debris layer result in greater attenuation and resulting returned powers that are less than observed. However, the basal reflector shows a great range in values based on our observations (Section 3.5; Table S7), with a standard deviation about the mean of $\pm 8.2 \mathrm{~dB}$. This range allows for a great variety of plausible debris thicknesses, which is consistent with the heterogeneous nature of debris properties observed across the study area (Sections 3.1 and 3.2). We also did not include the effects of surface roughness in our model, which would act to further attenuate the signal, leading to an even greater reduction in the power of the basal return and requiring very low internal losses in the upper debris layer (Petersen et al., 2017).

In summary, constraining the thickness of the supraglacial debris layer is difficult without improved constraints on the radar properties and basal topography of LDA, LVF, and CCF. If we assume average values for the thickness, radar return power at the base, and bulk $\varepsilon$ of LDA and LVF, the debris layer is estimated to be $<25 \mathrm{~m}$ with $\varepsilon \sim 4.0$. This is also consistent with the lack of near-surface reflections in SHARAD radargrams (Section 4.3.1). However, there is much variability in the power of the basal returns and basal topography that allow for debris layers that are thicker and with higher $\varepsilon$ (Petersen et al. 2018)). More fully characterizing the variability in radar properties of the LDA, LVF, and CCF basal reflections should help to better constrain the range of possible thicknesses and dielectric properties of the debris layer from radar data alone (Petersen et al., 2017; 2018).

\subsection{Origin of $L D A, L V F$, and CCF surface textures}

We suggest that the present variety of LDA, LVF, and CCF surface textures is mainly the result of emplacement and dissection of top icedust mantle layers, which act to modify underlying glacial structure. We suggest that the flow patterns/lineations and glacial structure of LDA, LVF, and CCF supraglacial debris are initially established within the layer of supraglacial rockfall. The rockfall is then covered by initially draping top layers of icy dust that are fractured due to tensional stresses arising from drape folds and thermal contraction and which are further modified by subsequent sublimation and thermal processing of internal ice, including enhancement along surface-breaking fractures (Mangold, 2003). In this way, the top mantle creates a topographic signature that is inherited from the underlying glacial structure but is further modified through sublimation of subsurface ice, thermal contraction, and erosion.

As shown, LDA, LVF, and CCF textures vary spatially across the region (Sections 2.2 and 3.1). There is clear clustering of texture development index (TDI) values (Fig. 4) that may result from a combination of latitude-dependent processes or variations in local geology or micro-climate. Latitude dependence of icy landforms on Mars has been interpreted to result from climate change induced by recent spin-axis obliquity variations (e.g., Head et al., 2003), with higher obliquity than present facilitating deposition of icy dust or mantle in the mid-latitudes. Upon return to lower obliquity, the mantle at the lowest latitudes is thermally unstable and is dissected through sublimation of internal ice and aeolian erosion. In line with previous workers (e.g., Mangold, 2003) we suggest that a similar process might be controlling the development of the major textural trends at the surfaces of LDA, 
a.

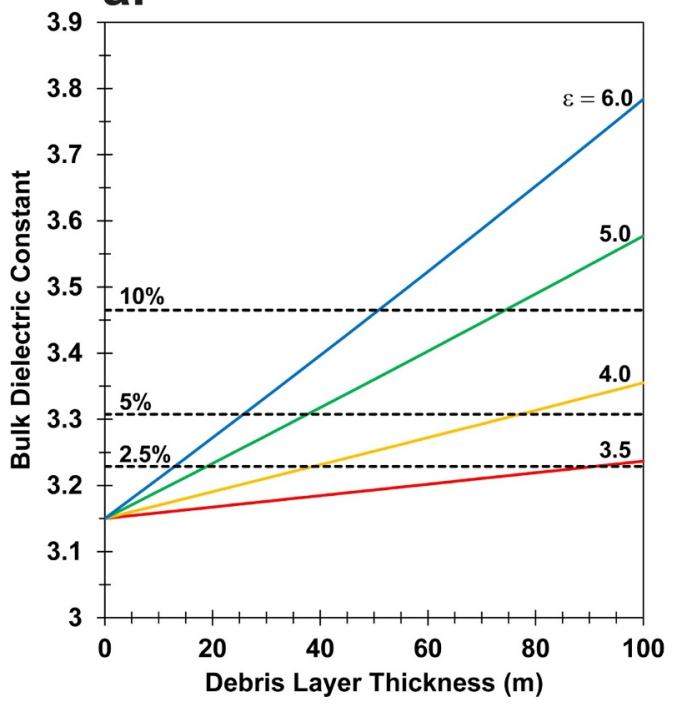

b.

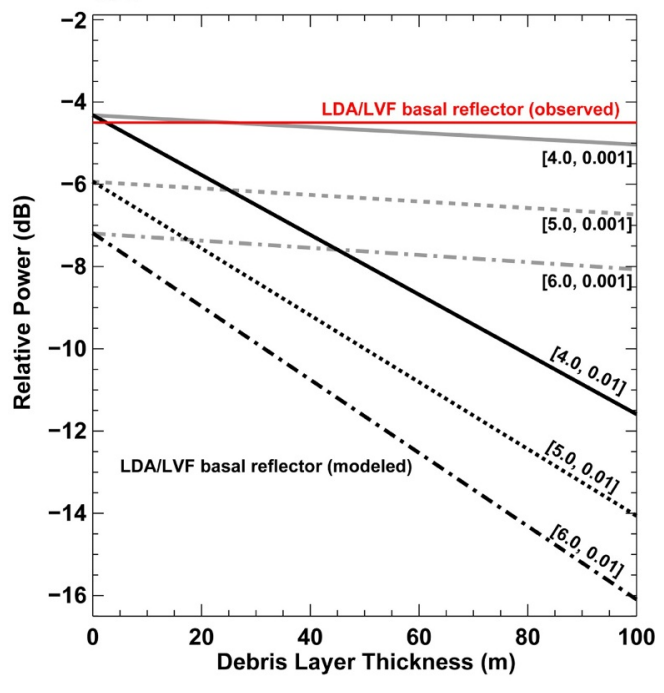

Fig. 21. (a) Modeled bulk dielectric constant of an LDA/LVF assuming a two-layer stratigraphy of debris on glacial ice. The permittivity and thickness of the debris layer is varied. Dashed lines for hypothetical uncertainties in the bulk value of 3.15 (Holt et al., 2008; Plaut et al., 2009) are plotted for reference. (b) Modeled power of a reflection off the base of LDA/LVF assuming various debris layer thicknesses, permittivities, and loss tangents $[\varepsilon, \tan \delta]$ (see Table D1, Model 2 ). The top red line at $-4.5 \mathrm{~dB}$ is the observed average power of reflections at the the base of LDA and LVF (Sections 2.8.2 and 4.3.2). Values for power are relative to the surface reflection. Most models produce reflections with powers that are much lower than observed, constraining the thickness and permittivity of the debris layer to be $<25 \mathrm{~m}$ and 4.0 , respectively.
LVF, and CCF (Figs. 4 and 8a). Our observations indicate thicker or less dissected mantle on LDA, LVF, and CCF northward of $44^{\circ} \mathrm{N}$, including surfaces with low TDI that are dominated by plateau and furrow textures and often lack lineations and "brain terrain" patterns (Fig. 5e). Low TDI values are also associated with slightly lower values of TES thermal inertia (Fig. 8b), which is consistent with greater coverage by mantle in these regions (Fig. 13). South of $44^{\circ} \mathrm{N}$, the plateau and furrow textures and mantle patches are absent, and more typical LDA, LVF, and CCF stippled or "brain terrain" textures with high TDI values are present. Further, high thermal inertia areas in the southern part of the study area (Fig. 13), corresponding to high surface boulder abundance and lack of mantle ridges, suggest possible removal of mantle or initially thinner mantle deposits at these locations. The latitude dependence of mantle modification is consistent with previous studies identifying dissection of ice-dust mantle units within $30^{\circ}$ to $50^{\circ}$ north and south latitude (Head et al., 2003; Milliken et al., 2003), and is consistent with the modeled stability of recently emplaced ice sheets on Mars (Schorghofer and Forget, 2012). Similar observations are reported for LDA in Tempe/Mareotis (Chuang and Crown, 2005; van Gasselt et al., 2011), where less prominent lineations are interpreted to result from the better preservation of mantle in this region compared with other regions such as Deuteronilus Mensae and in Eastern Hellas. Any latitude trend in texture would also be modulated by local variations in geology (e.g., headwall lithology, topographic catchments for accumulating airfall, etc.) or erosional processes (e.g., enhanced aeolian activity), explaining clusters of TDI values that deviate from the latitudinal trend (Fig. 4).

Our comprehensive analysis of crater landforms and crater sizefrequency distributions in the study area (Baker and Carter, 2019) further suggests that the thick mantle units that we interpret as responsible for many of the LDA, LVF, and CCF textures were repeatedly deposited and modified during the Middle Amazonian to Late Amazonian starting from the cessation of glacial flow $\sim 500$ Ma through to $\sim 100 \mathrm{Ma}$. This interpretation is based on the distinction between the size-frequency distributions of bowl-shaped craters, which are not modified by mantle layers, and so-called "ring-mold craters" (Kress and Head, 2008), which are interpreted to largely result from modification by thick mantle units (Baker and Carter, 2019). This interpretation is also consistent with other studies examining crater size-frequency distributions and crater morphology on LDA, LVF, and CCF (Mangold, 2003; Berman et al., 2015). These episodes of mantle emplacement are distinctly older than more recently emplaced $(<2 \mathrm{Ma})$ and thinner latitude-dependent mantle (Mustard et al., 2001; Head et al., 2003), which has also been shown to drape and modify portions of LDA, LVF, and CCF surfaces (Levy et al., 2010). The older $>100$ Ma age also suggests that the mantle could be recording the results of longer-term average trends in obliquity, and not just the most recent obliquity excursions over the past $2 \mathrm{Ma}$. If correct, the present textures on LDA, LVF, and CCF surfaces are the net result of hundreds of millions of years of accumulation and erosion of icy dust that post-date the end of major glaciation $\sim 500 \mathrm{Ma}$ and have continued until the present day.

\section{Conclusions and implications for accessibility of ice}

We present evidence for at least a two-layered structure for supraglacial debris of LDA, LVF, and CCG on Mars, which is summarized in Fig. 22. Layered mantle consisting of atmospherically emplaced dust and ice superposes boulder-rich sediment derived from rockfalls at the glacier headwalls. These rockfalls were glacially transported downslope to create a broad debris cover and narrower bands of concentrated debris that resemble terrestrial medial moraines. Downwasting of glacial ice over the features' $>400 \mathrm{Ma}$ age would have thickened this rockfall layer through development of a sublimation lag of sediment that may be a mixture of dust and larger clasts. The entire sediment package is at least a few meters thick and is more likely tens of meters in thickness, varying with the presence of mantle, latitude, and with distance from the headwall. The addition of many episodes of ice and dust deposition and erosion throughout the Amazonian have created a surface stratigraphy and surface terrain on LDA, LVF, and CCF, interpreted to be martian debris-covered glaciers, that is unique compared to terrestrial glaciers. The lack of terracing in craters formed within LDA, LVF, and CCF and the absence of near-surface reflectors in SHARAD radar data further suggest that no strong contrasts in permittivity or strength occur at the interface of the layers. This could result from a gradation in debris and ice content between the layers or more broad gradation in properties from the surface to pure glacial ice. Fully characterizing LDA, LVF, and CCF radar properties and additional modeling of crater modification in icy terrains are needed to provide improved constraints on the thickness of the debris.

While the estimated volumes of LDA, LVF, and CCF suggest the presence of massive reservoirs of non-polar ice at these locations, their accessibility is a limiting factor in remotely studying and using these reservoirs during future landed missions. The most advanced Mars robotic drilling techniques in development require ideal overburden thicknesses of less than a few meters (Hoffman et al., 2017). If correct, our observations of a debris layer that is a few to tens of meters in 


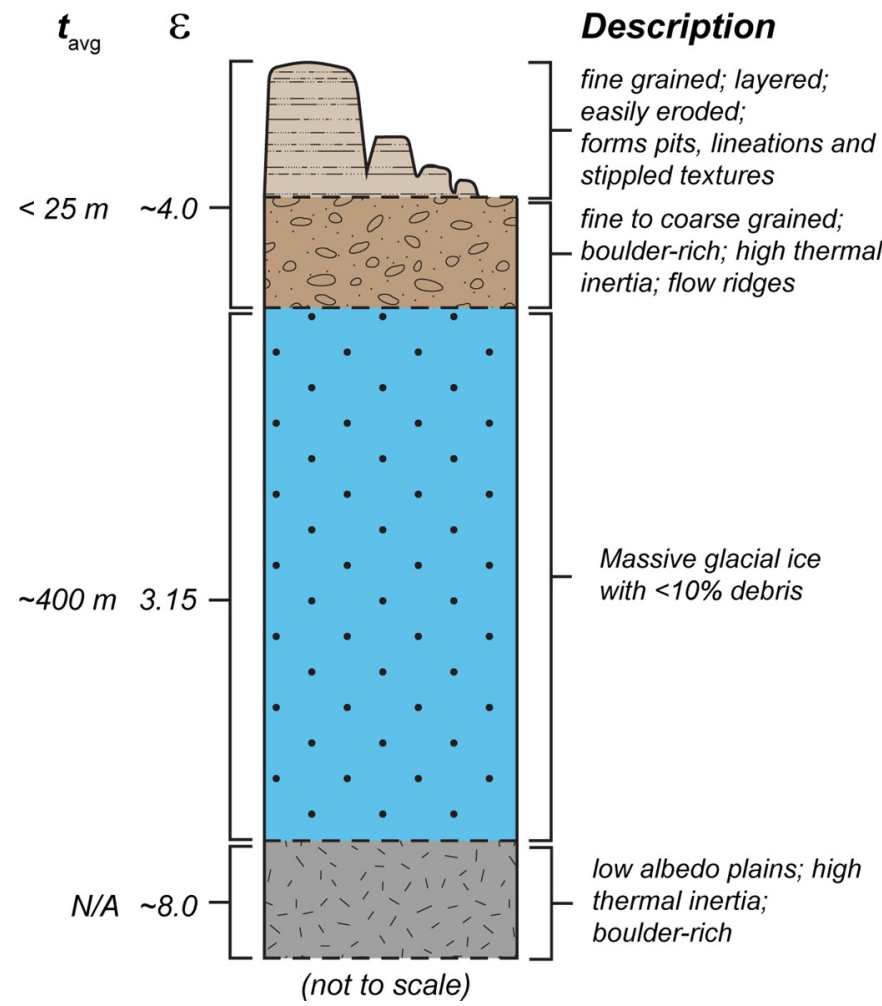

\section{Interpreted Source}

dust and ice airfall; repeated cycles of deposition

glacially transported rockfall

from headwall; lag of

englacial debris from

sublimation of glacial ice

accumulation of

atmospherically deposited

ice/snow; transported via

glacial flow

volcanic plains with younger

sedimentary material

Fig. 22. Sketch and description of inferred stratigraphy of LDA and LVF and supraglacial debris on Mars, with estimated average thickness $\left(t_{\text {avg }}\right)$ and permittivities $(\varepsilon)$.

thickness in many locations would present severe technical challenges for future robotic and human exploitation of these valuable water resources. The presence of a layer of rockfall or sublimation till with clasts up to $\sim 1 \mathrm{~m}$ in size would also present an obstacle for future technologies. Even on Earth, remote drilling within this type of material and on this scale is logistically challenging but feasible with the right equipment and resources (Hoffman et al., 2017). Future missions should seek out locations with the thinnest debris cover. Our observations suggest that these locations are most likely in regions with thin or no mantle cover and near the glacial headwalls but downslope of recent rockfall deposits. Possible ice layers within mantle superposing LDA, LVF, and CCF also could be a potentially more accessible water reservoir that may help pave the path toward later accessing glacial ice at depth. A future orbital or flight mission with a radar instrument at higher frequency than SHARAD would help to better map the depth to the seemingly abundant massive ice deposits in the mid-latitudes of Mars.

\section{Acknowledgements}

We thank very constructive reviews by Joseph Levy and an anonymous reviewer that helped to improve the quality of the manuscript. Thank you to Jay Dickson and Tim Goudge for help with Ames Stereo Pipeline tools and CTX DEM production. We thank members of the Mars Reconnaissance Orbiter and intrument teams for acquiring much of the data that were used in this work. This research was supported by an appointment to the NASA Postdoctoral Program at the NASA Goddard Space Flight Center, administered by Universities Space Research Association through a contract with NASA.

\section{Supplementary materials}

Supplementary material associated with this article can be found, in the online version, at doi:10.1016/j.icarus.2018.09.001.

\section{Appendix A. Crater diameter and depth measurements}

Crater depths were measured using two techniques: shadow length measurements and CTX DEM measurements (see Tables S3 and S4 for measurements). Shadow measurements were made on 61 CTX images and three HiRISE images with favorable solar incidence angles $55^{\circ} \geq i \leq 80^{\circ}$ (Daubar et al., 2014). Daubar et al. (2014) found that incidence angles less than this range produced anomalously low crater depth values and were therefore excluded from the analysis. A total of 56 craters $\geq 250 \mathrm{~m}$ in diameter that were covered by the images were measured. GIS software was used to first automatically draw a guide line from the mapped crater center to one crater radius in the direction of the solar azimuth angle for each image. The guide lines were then used to manually measure the geodesic distance from the crater rim to the tip of the shadow based on established methods summarized in Daubar et al. (2014) and based on the work of Chappelow and Sharpton (2002) and Barnouin et al. (2012). The tip of the shadow was taken as the mid-point between the observed complete shadow and diffuse shadow. The average of three measurements were taken for each crater; a total of 375 measurements of shadow length were collected. Measurements were made from multiple images if covering a single crater; 31 craters (over half) had two or more images. We also noted the shadow shape and inferred the interior crater geometry based on the methods of Chappelow and Sharpton (2002). Depth was calculated using the average shadow lengths, image geometry information, and appropriate formula based on the observed shadow geometry [Eqs. (A5), (A6), and (A7) in Daubar et al. (2014)]. Often, shadow geometries appeared differently in different images or were ambiguous between two geometries. For these cases, we averaged the calculated depths for all possible geometries to produce a single final depth for each crater. 


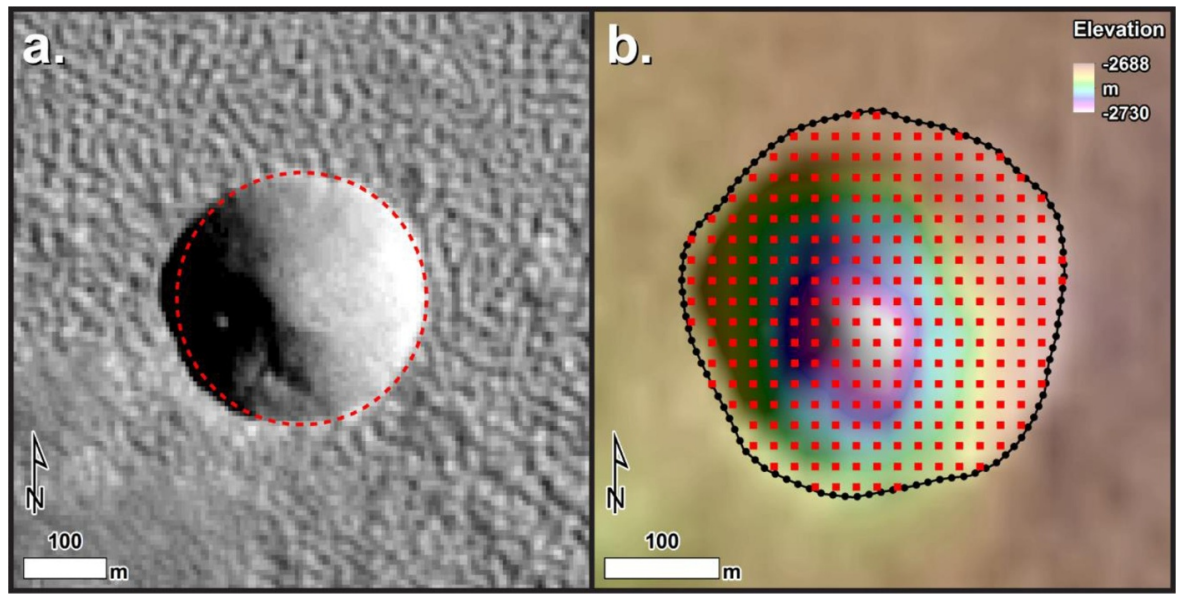

Fig. A1. (a) CTX image mosaic showing a circle fit to the rim crest of a well-preserved crater $(303 \mathrm{~m}$; $37.66^{\circ} \mathrm{N}, 24.39^{\circ} \mathrm{E}$ ). (b) Colored elevation from CTX DEM derived from CTX image pair G22_026994_2170_XI_37N335W and P03_002046 2180_XI_38N335W. Elevations at 100 equally spaced intervals were extracted (black points) along the rim trace (black line). All elevation values within the rim trace (red squares) were selected for finding the minimum interior elevation. (For interpretation of the references to color in this figure legend, the reader is referred to the web version of this article.)

Depths were also calculated from CTX DEMs (Fig. A1b). Possible CTX stereo image pairs were selected based on recommended image geometry limits described in Becker et al. (2015) and using the USGS Planetary Image Locator Tool (PILOT) (https://pilot.wr.usgs.gov/). A total of 17 CTX stereo pairs that covered 25 craters $\geq 250 \mathrm{~m}$ with nearby SHARAD tracks (Section 2.8.2) were selected for DEM production. DEMs were produced using USGS ISIS and Ames Stereo Pipeline (ASP) tools, as described in Moratto et al. (2010) and NASA Ames Research Center Intelligent Robotics Group (2017). Each DEM was tied to MOLA PEDR data and the martian areoid. Crater depth was calculated from the DEM as the difference between the crater rim elevation and the interior minimum. The rim crest of each crater was first manually traced from the rectified CTX image produced as an output of the ASP processing. A rim elevation value was then calculated from the average of DEM elevations at 100 equally spaced points along the rim trace. An interior minimum was calculated as the first percentile of all DEM pixels within the rim trace. The first percentile was chosen to avoid the possible effects of anomalously low elevation values or artifacts in the DEM.

\section{Appendix B. LDA and LVF thickness measurements}

For each SHARAD radargram, we identified a LDA, LVF, and CCF surface reflection and a basal reflection over a ten-pixel region in the range direction generally centered on the crater. The surface reflection was identified as the highest power value within a five-pixel buffer in the radargram sample direction surrounding the predicted surface based on MOLA gridded topography. The basal reflector was identified by first manually tracing the reflector in a subscene of the radargram. The final reflector was then automatically chosen as the highest power values within a five-pixel buffer in the sample direction surrounding this trace. The thickness of the glacier $(t)$ was then calculated from the velocity of the signal in the subsurface $(v)$ and the one-way travel time of the signal $(l)$ :

$t=v l$

The velocity was calculated as

$v=\frac{c}{\sqrt{\varepsilon}}$

where, $c=3 \times 10^{8} \mathrm{~m} / \mathrm{s}$. Consistent with previous estimates (Holt et al., 2008; Plaut et al., 2009), we assume $\varepsilon=3.15$, which is the real permittivity of ice. The one-way travel time was calculated as

$l=\frac{p n}{2}$

where, $p$ is the two-way travel time of one pixel (37.5 ns) and $n$ is the number of pixels between the surface and basal reflector. We report the final glacier thickness as the mean of thicknesses measured at each radargram column within the range buffer. Uncertainties are presented as $+/-$ one standard deviation from the mean (supplementary Table S7).

Each radargram was also compared to clutter simulations of surface echoes to verify that the identified basal reflectors were indeed due to subsurface interfaces (Fig. 7). Those reflections observed in the radargrams and not in the simulations were interpreted to be due to true reflectors at the base of the LDA, LVF, and CCF. We did not measure thicknesses for those radargrams obscured by surface echoes or where no basal reflector was present.

\section{Appendix C. Crater debris slumping model}

The shape and amount of debris slumped into a crater was modeled after the analytical expressions of Grieve and Garvin (1984), which compare well with field observations of the breccia lens and dimensions of terrestrial impact craters. Please refer to the appendix in that paper for a description of the model and relevant equations. We describe only the main features of the model here, with main parameters shown in Fig. C1. During crater formation, a paraboloid-shaped transient cavity is formed with a radius at the surface $R_{\mathrm{tc}}$ and a depth $d_{\mathrm{t}}$ where $d_{\mathrm{t}}=\mathrm{R}_{\mathrm{tc}} / 2^{0.5}$ (Dence, 1973). The radius of the transient cavity rim crest $\left(R_{\mathrm{tcr}}\right)$ is measured above the surface due to the structural uplift and ejecta material. For simple craters, the diameter of the transient cavity is increased by slumping of material into the crater, expanding $R_{\mathrm{tc}}$ by a factor of approximately 1.19 and reducing the floor depth (Grieve and Garvin, 1984; Melosh, 1989). The final crater has a final rim-crest radius $R_{\mathrm{r}}$ and a final depth after slumping, $d$, that is approximately $0.2 D_{\mathrm{r}}$ (Section 3.4). To approximate the amount of debris slumped inside the crater, we estimate the geometry of the transient cavity and the final crater by paraboloids, with the final crater depth prior to slumping equal to $d_{\mathrm{t}}$. The rim uplift for the final crater, $h_{\mathrm{r}}$, 


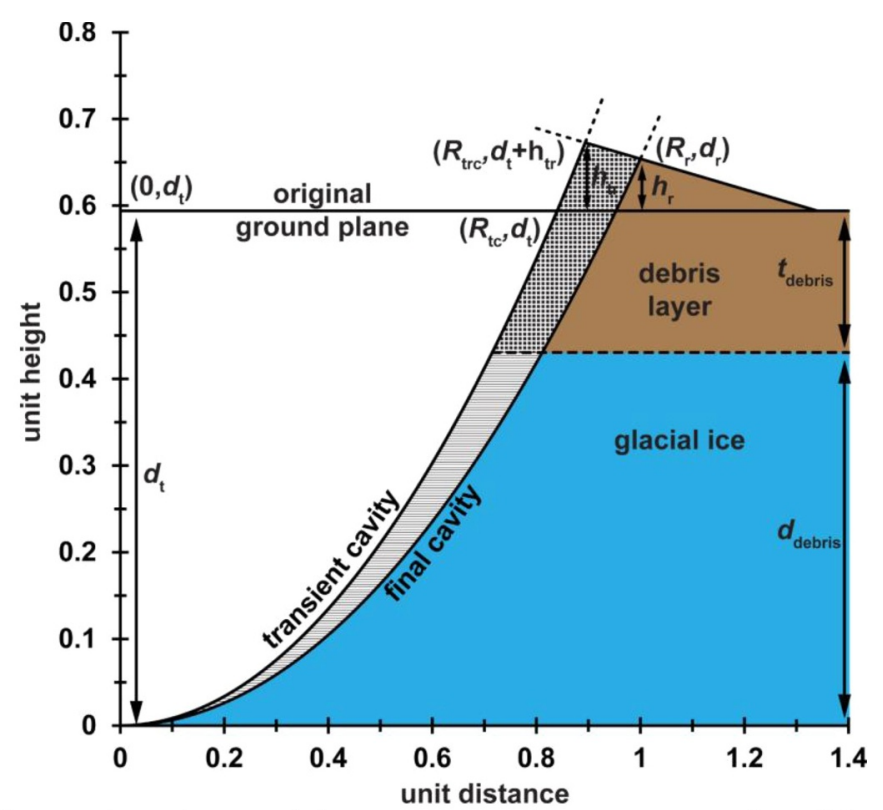

Fig. C1. Crater slumping model geometry and parameters, after Grieve and Garvin (1984). Variables are discussed in Appendix C.

is given from morphometric measurements of craters $<5 \mathrm{~km}$ from Watters et al. (2015) and was assumed to be $0.03 R_{\mathrm{r}}$. A slope of $10^{\circ}$ is assumed for the uplift profile (Grieve and Garvin, 1984) to approximate the location of the transient crater rim crest.

The volume of material slumped into the crater is calculated as an integral of revolution of the section between the transient and final crater paraboloids and the structural rim uplift above the surface. Due to the excavation into glacial ice, only a fraction of the slump material will be debris in our model. To calculate the amount of debris, we integrated from the base of the debris layer to the top of the rim profile. When the thickness of the debris layer is less than the excavation depth, a fraction of the rim uplift will be ice since it consists of both structural uplift and ejecta. For simplicity, we estimate the fraction of ice as the ratio of the thickness of the debris layer to the depth of excavation below the surface. The choice in estimating the ice fraction will have limited effect on the results due to the relatively small volume of the rim uplift compared to the rest of the slumped volume.

We assume that slumped ice is quickly sublimated and does not contribute to the interior debris cover. The remaining debris fraction is assumed to form a lens at the bottom of the crater, with a depth determined by the volume of debris and shape of the final crater paraboloid (Fig. 18). We expect that slumped debris will not be stable on the crater wall and will slide to fill the bottom of the crater. If the walls of the crater are ice, the static coefficient of friction between it and slumped debris is estimated to be near 0.5 or a slope of $26.6^{\circ}$ based on lab experiments between sand and ice blocks (Barker and Timco, 2003). Based on this static case and paraboloid geometries, all but the bottom $10 \%$ of the crater will be unstable to debris; slump debris coating the majority of the crater wall is therefore not expected.

\section{Appendix D. Radar transmission model}

A simple model for the transmission and reflection of radar waves through a layered target may established if the real permittivity $(\varepsilon)$, the loss $\operatorname{tangent}(\tan \delta$ ) and the thickness $(t)$ of each layer are known or estimated. The power reflected off the bottom of some $n$th layer for an $n+1$ layer stratigraphy can be written as

$P_{f}=P_{0} R_{n} \prod_{i=1}^{n} A_{i}^{2} T_{i}^{2}$

where $P_{\mathrm{f}}$ is the final returned power, $P_{0}$ is the initial nadir incident power at the surface, $T_{\mathrm{i}}$ is the power fraction transmitted through the top of the $i$ th layer, and $R_{\mathrm{i}}$ is the power fraction reflected from the bottom of the $i=n$ layer of interest. Reflection and transmission through an interface when the incident angle at the surface is zero can be found by

$R_{i}=\left(\frac{\sqrt{\varepsilon_{i+1}}-\sqrt{\varepsilon_{i}}}{\sqrt{\varepsilon_{i+1}}+\sqrt{\varepsilon_{i}}}\right)^{2}$

$T_{i}=1-R_{i}$

The one-way attenuation $(A)$ upon passage through a layer can be written as (Campbell, 2002)

$A_{i}=e^{-4 \pi \alpha_{i} t_{i}}$

$\alpha_{i}=\frac{1}{\lambda}\left[\frac{\varepsilon_{i}}{2}\left(\sqrt{1+\tan ^{2} \delta_{i}}-1\right)\right]^{0.5}$

where $\lambda$ is the SHARAD center wavelength $(15 \mathrm{~m})$. The values used for the two models described in Section 4.3 are given in Table D1. 
Table D1.

Parameters for radar transmission models.

\begin{tabular}{lll}
\hline Parameter & Model 1 & Model 2 \\
\hline Figure & $20 \mathrm{a}$ & $21 \mathrm{~b}$ \\
Layers & air-debris-ice & air-debris-ice-basement \\
$\varepsilon_{\text {debris }}$ & $2.0-10.0$ & $4.0,5.0,6.0$ \\
$\tan \delta_{\text {debris }}$ & $0.01,0.001,0.0001$ & $0.01,0.001,0.0001$ \\
$t_{\text {debris }}(\mathrm{m})$ & 10 & $15-50$ \\
\hline
\end{tabular}

For all models:

$\varepsilon_{\text {air }}=1$ and $\tan \delta_{\text {air }}=0$.

$\varepsilon_{\text {ice }}=3.15, \tan \delta_{\text {ice }}=0.002$ (Nunes and Phillips, 2006), and $t_{\text {ice }}=396-t_{\text {debris. }}$.

$\varepsilon_{\text {basement }}=8.0 ; \tan \delta_{\text {basement }}$ is not needed as the model considers reflections off the top of this layer.

\section{References}

Baker, D.M.H., 2018. Middle Amazonian accumulations of ice-rich dust in the mid-latitudes of Mars. In: Mars Workshop on Amazonian and Present Day Climate, Abstract 4035.

Baker, D.M.H., Head, J.W., 2015. Extensive Middle Amazonian mantling of debris aprons and plains in Deuteronilus Mensae, Mars: implications for the record of mid-latitude glaciation. Icarus 260, 269-288. https://doi.org/10.1016/j.icarus.2015.06.036.

Baker, D.M.H., Carter, L.M., 2019. Probing supraglacial debris on Mars 2: Crater morphology. Icarus 319, 264-280. https://doi.org/10.1016/j.icarus. 2018.09.009.

Baker, D.M.H., Head, J.W., Marchant, D.R., 2010. Flow patterns of lobate debris aprons and lineated valley fill north of Ismeniae Fossae, Mars: evidence for extensive mid latitude glaciation in the Late Amazonian. Icarus 207, 186-209. https://doi.org/10. 1016/j.icarus.2009.11.017.

Barker, A., Timco, G., 2003. The friction coefficient of a large ice block on a sand/gravel beach. In: 12th Workshop on the Hydraulics of Ice Covered Rivers. Edmonton, AB. pp. 16

Barnouin, O.S., Zuber, M.T., Smith, D.E., Neumann, G.A., Herrick, R.R., Chappelow, J.E., Murchie, S.L., Prockter, L.M., 2012. The morphology of craters on Mercury: results from MESSENGER flybys. Icarus 219, 414-427. https://doi.org/10.1016/j.icarus. 2012.02.029.

Bart, G.D., Nickerson, R.D., Lawder, M.T., Melosh, H.J., 2011. Global survey of lunar regolith depths from LROC images. Icarus 215, 485-490. https://doi.org/10.1016/j. icarus. 2011.07.017.

Becker, K.J., Archinal, B.A., Hare, T.H., Kirk, R.L., Howington-Kraus, E., Robinson, M.S., Rosiek, M.R., 2015. Criteria for automated identification of stereo image pairs. Lunar Planet. Sci. 46 Abstract 2703.

Benn, D.I., Evans, D.J.A., 1998. Glaciers and Glaciation. Arnold, London, pp. 734 pp.

Berman, D.C., Crown, D.A., Joseph, E.C.S., 2015. Formation and mantling ages of lobate debris aprons on Mars: insights from categorized crater counts. Planet. Space Sci. 111, 83-99. https://doi.org/10.1016/j.pss.2015.03.013.

Bramson, A.M., Byrne, S., Bapst, J., 2017. Preservation of midlatitude ice sheets on Mars. J. Geophys. Res. 122, 2250-2266. https://doi.org/10.1002/2017JE005357.

Bramson, A.M., Byrne, S., Putzig, N.E., Sutton, S., Plaut, J.J., Brothers, T.C., Holt, J.W., 2015. Widespread excess ice in Arcadia Planitia, Mars. Geophys. Res. Lett. 42, 6566-6574. https://doi.org/10.1002/2015GL064844.

Campbell, B.A., 2002. Radar Remote Sensing of Planetary Surfaces. Cambridge University Press, Cambridge, pp. 331 pp.

Campbell, B.A., Putzig, N.E., Carter, L.M., Morgan, G.A., Phillips, R.J., Plaut, J.J., 2013. Roughness and near-surface density of Mars from SHARAD radar echoes. J. Geophys. Res. Planets 118, 436-450. https://doi.org/10.1002/jgre.20050.

Cardenas, B.T., Lalich, D.E., Petersen, E., McKinnon, E.A., Andry, C.M., Nerozzi, S., Levy, J.S., Holt, J.W., 2014. Assessing the potential of debris-covered glaciers in the Uinta Mountains as martian analogs. Lunar Planet. Sci. 54 Abstract 2362.

Chappelow, J.E., Sharpton, V.L., 2002. An improved shadow measurement technique for constraining the morphometry of simple impact craters. Meteor. Planet. Sci. 37, 479-486. https://doi.org/10.1111/j.1945-5100.2002.tb00834.x.

Choudhary, P., Holt, J.W., Kempf, S.D., 2016. Surface clutter and echo location analysis for the interpretation of SHARAD data from Mars. IEEE Geosci. Remote Sens. Lett. 13, 1285-1289. https://doi.org/10.1109/LGRS.2016.2581799.

Christensen, P.R., Bandfield, J.L., Hamilton, V.E., Ruff, S.W., Kieffer, H.H., Titus, T.N., Malin, M.C., Morris, R.V., Lane, M.D., Clark, R.L., Jakosky, B.M., Mellon, M.T., Pearl, J.C., Conrath, B.J., Smith, M.D., Clancy, R.T., Kuzmin, R.O., Roush, T., Mehall, G.L., Gorelick, N., Bender, K., Murray, K., Dason, S., Greene, E., Silverman, S., Greenfield, M., 2001. Mars Global Surveyor Thermal Emission Spectrometer experiment: investigation description and surface science results. J. Geophys. Res. 106, 23823-23871. https://doi.org/10.1029/2000JE001370.

Christensen, P.R., Bandfield, J.L., B. Iii, F.J., Gorelick, N., Hamilton, V.E., Ivanov, A., Jakosky, B.M., Kieffer, H.H., Lane, M.D., Malin, M.C., McConnochie, T., McEwen, A.S., McSween, H.Y., Mehall, G.L., Moersch, J.E., Nealson, K.H., Rice, J.W., Richardson, M.I., Ruff, S.W., Smith, M.D., Titus, T.N., Wyatt, M.B., 2003. Morphology and composition of the surface of Mars: Mars Odyssey THEMIS results. Science 300, 2056-2061. https://doi.org/10.1126/science.1080885.

Chuang, F.C., Crown, D.A., 2009. Geologic Map of MTM 35337, 40337, and 45337 Quadrangles, Deuteronilus Mensae Region of Mars: U.S. Geological Survey Scientific Investigations Map 3079.

Chuang, F.C., Crown, D.A., 2005. Surface characteristics and degradational history of debris aprons in the Tempe Terra/Mareotis fossae region of Mars. Icarus 179, 24-42. https://doi:10.1016/j.icarus.2005.05.014.

Craddock, R.A., Maxwell, T.A., Howard, A.D., 1997. Crater morphometry and modification in the Sinus Sabaeus and Margaritifer Sinus regions of Mars. J. Geophys. Res. 102, 13321-13340. https://doi.org/10.1029/97JE01084.

Croft, S.K., 1980. Cratering flow fields: implications for the excavation and transient expansion stages of crater formation. In: Proc. Lunar Planet. Sci. Conf. 11th, pp. 2347-2378.

Daubar, I.J., Atwood-Stone, C., Byrne, S., McEwen, A.S., Russell, P.S., 2014. The morphology of small fresh craters on Mars and the Moon. J. Geophys. Res. 119, 2620-2639. https://doi.org/10.1002/2014JE004671.

Dence, M.R., 1973. Dimensional analysis of impact structures. Meteoritics 8, 343-344.

de Smith, M., Goodchild, M., Longley, P., 2015. Geospatial Analysis, fifth ed. Available online at: http://www.spatialanalysisonline.com/.

Dickson, J.L., Head, J.W., Marchant, D.R., 2008. Late Amazonian glaciation at the dichotomy boundary on Mars: evidence for glacial thickness maxima and multiple glacial phases. Geology 36, 411-414. https://doi.org/10.1130/G24382A.1.

Dundas, C.M., 2017. Effects of varying obliquity on Martian sublimation thermokarst landforms. Icarus 281, 115-120. https://doi.org/10.1016/j.icarus.2016.08.031.

Dundas, C.M., Byrne, S., McEwen, A.S., 2015. Modeling the development of martian sublimation thermokarst landforms. Icarus 262, 154-169. https://doi.org/10.1016/j. icarus.2015.07.033.

Dundas, C.M., Byrne, S., McEwen, A.S., Mellon, M.T., Kennedy, M.R., Daubar, I.J., Saper, L., 2014. HiRISE observations of new impact craters exposing Martian ground ice. J. Geophys. Res. 119, 2013JE004482. https://doi.org/10.1002/2013JE004482.

Dundas, C.M., Bramson, A.M., Ojha, L., Wray, J.J., Mellon, M.T., Byrne, S., McEwen, A.S. Putzig, N.E., Viola, D., Sutton, S., Clark, E., Holt, J.W., 2018. Exposed subsurface ice sheets in the Martian mid-latitudes. Science 359, 199-201. https://doi.org/10.1126/ science.aao1619.

Edwards, C.S., Nowicki, K.J., Christensen, P.R., Hill, J., Gorelick, N., Murray, K., 2011. Mosaicking of global planetary image datasets: 1 . Techniques and data processing for Thermal Emission Imaging System (THEMIS) multi-spectral data. J. Geophys. Res. 116, E10008. https://doi.org/10.1029/2010JE003755.

Fassett, C.I., Levy, J.S., Dickson, J.L., Head, J.W., 2014. An extended period of episodic northern mid-latitude glaciation on Mars during the Middle to Late Amazonian: implications for long-term obliquity history. Geology 42, 763-766. https://doi.org/ 10.1130/G35798.1.

Fastook, J.L., Head, J.W., Marchant, D.R., 2014. Formation of lobate debris aprons on Mars: assessment of regional ice sheet collapse and debris-cover armoring. Icarus 228, 54-63. https://doi.org/10.1016/j.icarus.2013.09.025.

Fergason, R.L., Christensen, P.R., Kieffer, H.H., 2006. High-resolution thermal inertia derived from the Thermal Emission Imaging System (THEMIS): thermal model and applications. J. Geophys. Res. 111, E12004. https://doi.org/10.1029/ 2006JE002735.

Gertsch, L.S., Rostami, J., Gustafson, R., 2008. Review of lunar regolith properties for design of low power lunar excavators. In: Sixth International Conference on Case Histories in Geotechnical Engineering, Paper No. 10.02.

Grieve, R.A.F., Garvin, J.B., 1984. A geometric model for excavation and modification at terrestrial simple impact craters. J. Geophys. Res. 89, 11561-11572. https://doi.org/ 10.1029/JB089iB13p11561.

Haeberli, W., Hallet, B., Arenson, L., Elconin, R., Humlum, O., Kääb, A., Kaufmann, V., Ladanyi, B., Matsuoka, N., Springman, S., Mühll, D.V., 2006. Permafrost creep and rock glacier dynamics. Permafrost Periglacial Proc. 17, 189-214. https://doi.org/10. 1002/ppp.561.

Hartmann, W.K., 2005. Martian cratering 8: isochron refinement and the chronology of Mars. Icarus 174, 294-320. https://doi.org/10.1016/j.icarus.2004.11.023.

Hartmann, W.K., 1971. Martian cratering III: theory of crater obliteration. Icarus 15, 410-428. https://doi.org/10.1016/0019-1035(71)90119-9.

Hartmann, W.K., Neukum, G., 2001. Cratering chronology and the evolution of Mars. Space Sci. Rev 96, 165-194. https://doi.org/10.1023/A:1011945222010.

Haynes, R.D., 1978. Effect of Temperature on the Strength of Snow-Ice. pp. 19 U.S. Army Cold Regions Research and Engineering Laboratory (CRREL) Report 78-27.

Head, J., Dickson, J., Mustard, J., Milliken, R., Scott, D., Johnson, B., Marchant, D., Levy, J., Kinch, K., Hvidberg, C., Forget, F., Boucher, D., Mikucki, J., Fastook, J., Klaus, K., 2015. Mars human science exploration and resource utilization: the dichotomy boundary Deuteronilus Mensae exploration zone. In: First Landing Site/Exploration Zone Workshop for Human Missions to the Surface of Mars, Abstract 1033.

Head, J.W., Marchant, D.R., Dickson, J.L., Kress, A.M., Baker, D.M., 2010. Northern mid- 
latitude glaciation in the Late Amazonian period of Mars: criteria for the recognition of debris-covered glacier and valley glacier landsystem deposits. Earth Planet. Sci. Lett. 294, 306-320. https://doi.org/10.1016/j.epsl.2009.06.041.

Head, J.W., Mustard, J.F., Kreslavsky, M.A., Milliken, R.E., Marchant, D.R., 2003. Recent ice ages on Mars. Nature 426, 797-802. https://doi.org/10.1038/nature02114.

Head, J.W., Marchant, D.R., Agnew, M.C., Fassett, C.I., Kreslavsky, M.A., 2006a. Extensive valley glacier deposits in the northern mid-latitudes of Mars: evidence for Late Amazonian obliquity-driven climate change. Earth Planet. Sci. Lett. 241, 663-671. https://doi.org/10.1016/j.epsl.2005.11.016.

Head, J.W., Nahm, A.L., Marchant, D.R., Neukum, G., 2006b. Modification of the dichotomy boundary on Mars by Amazonian mid-latitude regional glaciation. Geophys. Res. Lett. 33, L08S03. https://doi.org/10.1029/2005GL024360.

Hoffman, S.J.A., 2017. A water rich Mars surface mission scenario. In: IEEE Aerospace Conference, pp. 21 p.

Holt, J.W., Safaeinili, A., Plaut, J.J., Head, J.W., Phillips, R.J., Seu, R., Kempf, S.D., Choudhary, P., Young, D.A., Putzig, N.E., Biccari, D., Gim, Y., 2008. Radar sounding evidence for buried glaciers in the southern mid-latitudes of Mars. Science 322, 1235-1238. https://doi.org/10.1126/science.1164246.

Kadish, S.J., Barlow, N.G., Head, J.W., 2009. Latitude dependence of Martian pedestal craters: evidence for a sublimation-driven formation mechanism. J. Geophys. Res. 114, E10001. https://doi.org/10.1029/2008JE003318.

Kadish, S.J., Head, J.W., 2014. The ages of pedestal craters on Mars: evidence for a lateAmazonian extended period of episodic emplacement of decameters-thick mid-latitude ice deposits. Planet. Space Sci. 91, 91-100. https://doi.org/10.1016/j.pss.2013. 12.003

Karlsson, N.B., Schmidt, L.S., Hvidberg, C.S., 2015. Volume of Martian midlatitude glaciers from radar observations and ice flow modeling. Geophys. Res. Lett. 42 2627-2633. https://doi.org/10.1002/2015GL063219.

Kneissl, T., van Gasselt, S., Neukum, G., 2011. Map-projection-independent crater sizefrequency determination in GIS environments-New software tool for ArcGIS. Planet. Space Sci. 59, 1243-1254. https://doi.org/10.1016/j.pss.2010.03.015.

Kostama, V.-P., Kreslavsky, M.A., Head, J.W., 2006. Recent high-latitude icy mantle in the northern plains of Mars: characteristics and ages of emplacement. Geophys. Res. Lett. 33, L11201. https://doi.org/10.1029/2006GL025946.

Koutnik, M.R., Pathare, A.V., Todd, C., Waddington, E., Christian, J.E., 2016. Applying knowledge from terrestrial debris-covered glaciers to constrain the evolution of martian debris-covered ice. In: Sixth International Conference on Mars Polar Science and Exploration, Abstract 6065

Kress, A.M., Head, J.W., 2008. Ring-mold craters in lineated valley fill and lobate debris aprons on Mars: evidence for subsurface glacial ice. Geophys. Res. Lett. 35, L23206. https://doi.org/10.1029/2008GL035501.

Laskar, J., Correia, A.C.M., Gastineau, M., Joutel, F., Levrard, B., Robutel, P., 2004. Long term evolution and chaotic diffusion of the insolation quantities of Mars. Icarus 170, 343-364. https://doi.org/10.1016/j.icarus.2004.04.005.

Levy, J.S., Marchant, D.R., Head, J.W., 2006. Distribution and origin of patterned ground on Mullins Valley debris-covered glacier, Antarctica: the roles of ice flow and sublimation. Antarctic Sci. 18, 385-397. https://doi.org/10.1017/S0954102006000435.

Levy, J., Head, J., Marchant, D., 2009a. Thermal contraction crack polygons on Mars: classification, distribution, and climate implications from HiRISE observations. J. Geophys. Res. 114, E01007. https://doi.org/10.1029/2008JE003273.

Levy, J.S., Head, J.W., Marchant, D.R., 2009b. Concentric crater fill in Utopia Planitia: history and interaction between glacial "brain terrain" and periglacial mantle processes. Icarus 202, 462-476. https://doi.org/10.1016/j.icarus.2009.02.018.

Levy, J.S., Marchant, D.R., Head, J.W., 2010. Thermal contraction crack polygons on Mars: a synthesis from HiRISE, Phoenix, and terrestrial analog studies. Icarus 206, 229-252. https://doi.org/10.1016/j.icarus.2009.09.005.

Levy, J.S., Fassett, C.I., Head, J.W., Schwartz, C., Watters, J.L., 2014. Sequestered glacial ice contribution to the global Martian water budget: geometric constraints on the volume of remnant, midlatitude debris-covered glaciers. J. Geophys. Res. 119, 2188-2196. https://doi.org/10.1002/2014JE004685.

Levy, J.S., Fassett, C.I., Head, J.W., 2016. Enhanced erosion rates on Mars during Amazonian glaciation. Icarus 264, 213-219. https://doi.org/10.1016/j.icarus.2015. 09.037.

Li, H., Robinson, M.S., Jurdy, D.M., 2005. Origin of martian northern hemisphere midlatitude lobate debris aprons. Icarus 176, 382-394. https://doi.org/10.1016/j.icarus. 2005.02 .011$.

Lucchitta, B.K., 1984. Ice and debris in the Fretted Terrain, Mars. J. Geophys. Res. 89, B409-B418. https://doi.org/10.1029/JB089iS02p0B409.

Madeleine, J.-B., Forget, F., Head, J.W., Levrard, B., Montmessin, F., Millour, E., 2009 Amazonian northern mid-latitude glaciation on Mars: a proposed climate scenario. Icarus 203, 390-405. https://doi.org/10.1016/j.icarus.2009.04.037.

Madeleine, J.-B., Head, J.W., Forget, F., Navarro, T., Millour, E., Spiga, A., Colaïtis, A. Määttänen, A., Montmessin, F., Dickson, J.L., 2014. Recent ice ages on Mars: the role of radiatively active clouds and cloud microphysics. Geophys. Res. Lett. 41, 4873-4879. https://doi.org/10.1002/2014GL059861.

Malin, M.C., Bell, J.F., Cantor, B.A., Caplinger, M.A., Calvin, W.M., Clancy, R.T., Edgett, K.S., Edwards, L., Haberle, R.M., James, P.B., Lee, S.W., Ravine, M.A., Thomas, P.C., Wolff, M.J., 2007. Context Camera Investigation on board the Mars Reconnaissance Orbiter. J. Geophys. Res. 112, E05S04 https://doi.org/10.1029/2006JE002808.

Mangold, N., 2003. Geomorphic analysis of lobate debris aprons on Mars at Mars Orbiter Camera scale: evidence for ice sublimation initiated by fractures. J. Geophys. Res. 108, 8021. https://doi.org/10.1029/2002JE001885.

Marchant, D.R., Head, J.W., 2007. Antarctic dry valleys; microclimate zonation, variable geomorphic processes, and implications for assessing climate change on Mars. Icarus 192, 187-222. https://doi.org/10.1016/j.icarus.2007.06.018.

Marchant, D.R., Lewis, A.R., Phillips, W.M., Moore, E.J., Souchez, R.A., Denton, G.H.,
Sugden, D.E., Potter, N., Landis, G.P., 2002. Formation of patterned ground and sublimation till over Miocene glacier ice in Beacon Valley, Southern Victoria Land, Antarctica. GSA Bulletin 114, 718-730. https://doi.org/10.1130/0016-7606(2002) $114<0718$ :FOPGAS > 2.0.CO;2.

Mackay, S.L., Marchant, D.R., Lamp, J.L., Head, J.W., 2014. Cold-based debris-covered glaciers: evaluating their potential as climate archives through studies of groundpenetrating radar and surface morphology. J. Geophys. Res. Earth Surf. 119, 2505-2540. https://doi.org/10.1002/2014JF003178.

McEwen, A.S., Eliason, E.M., Bergstrom, J.W., Bridges, N.T., Hansen, C.J., Delamere, W.A., Grant, J.A., Gulick, V.C., Herkenhoff, K.E., Keszthelyi, L., Kirk, R.L., Mellon, M.T., Squyres, S.W., Thomas, N., Weitz, C.M., 2007. Mars Reconnaissance Orbiter's High Resolution Imaging Science Experiment (HiRISE). J. Geophys. Res. 112 , E05S02. https://doi.org/10.1029/2005JE002605.

Mellon, M.T., Jakosky, B.M., 1993. Geographic variations in the thermal and diffusive stability of ground ice on Mars. J. Geophys. Res. 98, 3345-3364. https://doi.org/10 1029/92JE02355.

Mellon, M.T., Jakosky, B.M., 1995. The distribution and behavior of Martian ground ice during past and present epochs. J. Geophys. Res. 100, 11781-11799.

Mellon, M.T., Kretke, K.A., Smith, M.D., Pelkey, S.M., 2002. A global map of thermal inertia from Mars Global Surveyor mapping-mission data. Lunar Planet. Sci. 33 Abstract 1416.

Melosh, H.J., 1989. Impact Cratering: A Geologic Process. Oxford University Press, London, pp. 253 pp.

Milliken, R.E., Mustard, J.F., Goldsby, D.L., 2003. Viscous flow features on the surface of Mars: observations from high-resolution Mars Orbiter Camera (MOC) images. J. Geophys. Res. 108, 5057. https://doi.org/10.1029/2002JE002005.

Moratto, Z.M., Broxton, M.J., Beyer, R.A., Lundy, M., Husmann, K., 2010. Ames Stereo Pipeline, NASA's open source automated stereogrammetry software. Lunar Planet. Sci. 41 Abstract 2364.

Morgan, G.A., Head III, J.W., 2009. Sinton crater, Mars: evidence for impact into a plateau icefield and melting to produce valley networks at the Hesperian-Amazonian boundary. Icarus 202, 39-59. https://doi.org/10.1016/j.icarus.2009.02.025.

Morgan, G.A., Head III, J.W., Marchant, D.R., 2009. Lineated valley fill (LVF) and lobate debris aprons (LDA) in the Deuteronilus Mensae northern dichotomy boundary region, Mars: constraints on the extent, age and episodicity of Amazonian glacial events. Icarus 202, 22-38. https://doi.org/10.1016/j.icarus.2009.02.017.

Mouginis-Mark, P.J., Boyce, J., Sharpton, V.L., Garbeil, H., 2017. Determination of Mars crater geometric data: insights from high-resolution digital elevation models. Meteorit. Planet. Sci. 1-15. https://doi.org/10.1111/maps.12895.

Mustard, J.F., Cooper, C.D., Rifkin, M.K., 2001. Evidence for recent climate change on Mars from the identification of youthful near-surface ground ice. Nature 412 411-414. https://doi.org/10.1038/35086515.

NASA Ames Research Center Intelligent Robotics Group, 2017. The Ames Stereo Pipeline: NASA's Open Source Automated Stereogrammetry Software. Available form: https://ti.arc.nasa.gov/tech/asr/intelligent-robotics/ngt/stereo/, November 2017.

Nield, J.M., Chiverrell, R.C., Darby, S.E., Leyland, J., Vircavs, L.H., Jacobs, B., 2013 Complex spatial feedbacks of tephra redistribution, ice melt and surface roughness modulate ablation on tephra covered glaciers. Earth Surf. Process. Landforms 38, 95-102. https://doi.org/10.1002/esp.3352.

Nowicki, S.A., Christensen, P.R., 2007. Rock abundance on Mars from the Thermal Emission Spectrometer. J. Geophys. Res. 112, E05007. https://doi.org/10.1029/ 2006JE002798.

Nunes, D.C., Phillips, R.J., 2006. Radar subsurface mapping of the polar layered deposits on Mars. J. Geophys. Res. 111, E06S21. https://doi.org/10.1029/2005JE002609.

Parsons, R.A., Nimmo, F., Miyamoto, H., 2011. Constraints on martian lobate debris apron evolution and rheology from numerical modeling of ice flow. Icarus 214 , 246-257. https://doi.org/10.1016/j.icarus.2011.04.014.

Petersen, E.I., Holt, J.W., Levy, J.S., Goudge, T.A., 2017. New constraints on surface debris layer composition for martian mid-latitude glaciers from SHARAD and HiRISE. Lunar Planet. Sci. 48 Abstract 2767.

Petersen, E.I., Levy, J.S., Holt, J.W., McKinnon, E.A., Goudge, T.A., 2016. The effect of surface roughness on shallow radar sounding of debris-covered glaciers in Deuteronilus Mensae, Mars. Lunar Planet. Sci. 47 Abstract 2618.

Petersen, E.I., Holt, J.W., Levy, J.S., 2018. All Our Aprons are Icy: No Evidence for Debris Rich "Lobate Debris Aprons" in Deuteronilus Mensae. Lunar Planet. Sci. Conf. 49 Abstract 2354

Piatek, J.L., 2009. Thermophysical properties of terrestrial rock and debris-covered glaciers as analogs for martian lobate debris aprons. Lunar Planet. Sci. 40 Abstract 2127.

Piatek, J.L., 2008. Thermophysical properties of proposed glacial features on Mars. Lunar Planet. Sci. 39 Abstract 1485.

Pierce, T.L., Crown, D.A., 2003. Morphologic and topographic analyses of debris aprons in the eastern Hellas region, Mars. Icarus 163, 46-65. https://doi.org/10.1016/ S0019-1035(03)00046-0.

Plaut, J.J., Safaeinili, A., Holt, J.W., Phillips, R.J., Head, J.W., Seu, R., Putzig, N.E., Frigeri, A., 2009. Radar evidence for ice in lobate debris aprons in the mid-northern latitudes of Mars. Geophys. Res. Lett. 36, L02203. https://doi.org/10.1029/ 2008GL036379.

Putzig, N.E., Mellon, M.T., 2007. Apparent thermal inertia and the surface heterogeneity of Mars. Icarus 191, 68-94. https://doi.org/10.1016/j.icarus.2007.05.013.

Putzig, N.E., Phillips, R.J., Campbell, B.A., Mellon, M.T., Holt, J.W., Brothers, T.C., 2014 SHARAD soundings and surface roughness at past, present, and proposed landing sites on Mars: reflections at Phoenix may be attributable to deep ground ice. J. Geophys. Res. Planets 119, 1936-1949. https://doi.org/10.1002/2014JE004646.

Putzig, N.E., Phillips, R.J., Campbell, B.A., Plaut, J.J., Holt, J.W., Bernardini, F., Egan, A.F., Smith, I.B., 2016. Custom SHARAD processing via the CO-SHARPS processing boutique. Lunar Planet. Sci. 47 Abstract 3010. 
Quaide, W.L., Oberbeck, V.R., 1968. Thickness determinations of the lunar surface layer from lunar impact craters. J. Geophys. Res. 73, 5247-5270. https://doi.org/10.1029/ JB073i016p05247.

Ramsdale, J.D., Balme, M.R., Conway, S.J., Gallagher, C., van Gasselt, S.A., Hauber, E., Orgel, C., Séjourné, A., Skinner, J.A., Costard, F., Johnsson, A., Losiak, A., Reiss, D., Swirad, Z.M., Kereszturi, A., Smith, I.B., Platz, T., 2017. Grid-based mapping: a method for rapidly determining the spatial distributions of small features over very large areas. Planet. Space Sci. 140, 49-61. https://doi.org/10.1016/j.pss.2017.04. 002.

Schon, S.C., Head, J.W., Milliken, R.E., 2009. A recent ice age on Mars: evidence for climate oscillations from regional layering in mid-latitude mantling deposits. Geophys. Res. Lett. 36, L15202. https://doi.org/10.1029/2009GL038554.

Schorghofer, N., Forget, F., 2012. History and anatomy of subsurface ice on Mars. Icarus 220, 1112-1120. https://doi.org/10.1016/j.icarus.2012.07.003.

Senft, L.E., Stewart, S.T., 2007. Modeling impact cratering in layered surfaces. J. Geophys. Res. 112, E11002. https://doi.org/10.1029/2007JE002894.

Senft, L.E., Stewart, S.T., 2008. Impact crater formation in icy layered terrains on Mars. Meteorit. Planet. Sci. 43, 1993-2013. https://doi.org/10.1111/j.1945-5100.2008. tb00657.x.

Seu, R., Phillips, R.J., Biccari, D., Orosei, R., Masdea, A., Picardi, G., Safaeinili, A., Campbell, B.A., Plaut, J.J., Marinangeli, L., Smrekar, S.E., Nunes, D.C., 2007. SHARAD sounding radar on the Mars Reconnaissance Orbiter. J. Geophys. Res. 112, E05S05. https://doi.org/10.1029/2006JE002745.

Sharp, R.P., 1973. Mars: fretted and chaotic terrains. J. Geophys. Res. 78, 4073-4083. https://doi.org/10.1029/JB078i020p04073.

Skinner, J.A., Tanaka, K.L., Platz, T., 2012. Widespread loess-like deposit in the Martian northern lowlands identifies Middle Amazonian climate change. Geology 40, 1127-1130. https://doi.org/10.1130/G33513.
Sletten, R.S., Hallet, B., Fletcher, R.C., 2003. Resurfacing time of terrestrial surfaces by the formation and maturation of polygonal patterned ground. J. Geophys. Res. 108, E48044. https://doi.org/10.1029/2002JE001914.

Soare, R.J., Conway, S.J., Gallagher, C., Dohm, J.M., 2017. Ice-rich (periglacial) vs icy (glacial) depressions in the Argyre region, Mars: a proposed cold-climate dichotomy of landforms. Icarus 282, 70-83. https://doi.org/10.1016/j.icarus.2016.09.009.

Souness, C., Hubbard, B., Milliken, R.E., Quincey, D., 2012. An inventory and populationscale analysis of martian glacier-like forms. Icarus 217, 243-255. https://doi.org/10. 1016/j.icarus.2011.10.020.

Squyres, S.W., 1978. Martian fretted terrain: flow of erosional debris. Icarus 34, 600-613. https://doi.org/10.1016/0019-1035(78)90048-9.

Squyres, S.W., 1979. The distribution of lobate debris aprons and similar flows on Mars. J. Geophys. Res. 84, 8087-8096. https://doi.org/10.1029/JB084iB14p08087.

van Gasselt, S., Hauber, E., Neukum, G., 2010. Lineated valley fill at the Martian dichotomy boundary: nature and history of degradation. J. Geophys. Res. 115, E08003. https://doi.org/10.1029/2009JE003336.

van Gasselt, S., Hauber, E., Rossi, A.-P., Dumke, A., Orosei, R., Neukum, G., 2011. Periglacial geomorphology and landscape evolution of the Tempe Terra region, Mars. In: Balme, M.R., Bargery, A.S., Gallagher, C.J., Gupta, S. (Eds.), Martian Geomorphology 356. Geol. Soc. London. Spec. Pub, pp. 43-67.. https://doi.org/10. 1144/SP356.4.

Viola, D., McEwen, A.S., Dundas, C.M., Byrne, S., 2015. Expanded secondary craters in the Arcadia Planitia region, Mars: evidence for tens of Myr-old shallow subsurface ice. Icarus 248, 190-204. https://doi.org/10.1016/j.icarus.2014.10.032.

Watters, W.A., Geiger, L.M., Fendrock, M., Gibson, R., 2015. Morphometry of small recent impact craters on Mars: size and terrain dependence, short-term modification. J. Geophys. Res. 120, 226-254. https://doi.org/10.1002/2014JE004630. 